DIVISION OF THE HUMANITIES AND SOCIAL SCIENCES

CALIFORNIA INSTITUTE OF TECHNOLOGY

PASADENA, CALIFORNIA 91125

ON THE MICROSTRUCTURE OF PRICE DETERMINATION AND INFORMATION AGGREGATION WITH SEQUENTIAL AND ASYMMETRIC INFORMATION ARRIVAL IN AN EXPERIMENTAL ASSET MARKET

Martin Barner

University of Copenhagen

Francesco Feri

Universita Ca Foscari di Venezia, University of Venice

Charles R. Plott

California Institute of Technology

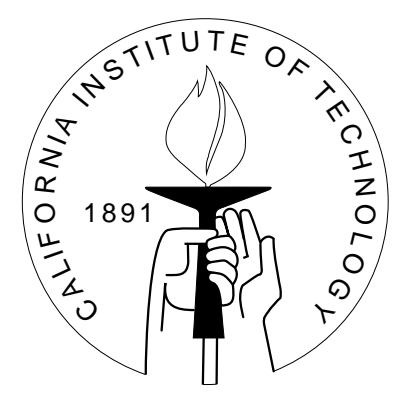

SOCIAL SCIENCE WORKING PAPER 1204 


\title{
On The Microstructure of Price Determination And Information Aggregation With Sequential And Asymmetric Information Arrival in an Experimental Asset Market
}

\author{
Martin Barner Francesco Feri Charles R. Plott
}

\begin{abstract}
Experiments were conducted on an asset with the structure of an option. The information of any individual is limited, as if only the direction of movement of the option value known for a single period without information of the value from when movement was initiated. However, if all information of all insiders were pooled, the value of the option would be known with certainty. The results are the following: (1) Information becomes aggregated in the prices as if fully informative rational expectations operated; and (2) The mechanism through which information gets into the market is captured by a path dependent process that we term "The Fundamental Coordination Principle of Information Transfer in Competitive Markets". The early contracts tend to be initiated by insiders who tender limit orders. The emergence of bubbles and mirages in the markets are coincident with failures and circumstances that prevent the operation of the "Fundamental Principle."
\end{abstract}

JEL classification numbers: D4, G10, C92, D44, D82

Key words: Microstructure Information, Rational Expectations Experiments, Information Aggregation, Belief Formation, Bubbles, Cascades 


\title{
ON THE MICROSTRUCTURE OF PRICE DETERMINATION AND INFORMATION AGGREGATION WITH SEQUENTIAL AND ASYMMETRIC INFORMATION ARRIVAL IN AN EXPERIMENTAL ASSET MARKET
}

\author{
Martin Barner ${ }^{1}$, Francesco Feri ${ }^{2}$ and Charles R. Plott ${ }^{3}$
}

\section{Introduction ${ }^{4}$}

This paper is motivated by the capacity of asset markets to adjust to the time dynamics of partial information about returns including information that is asymmetrically held by different individuals at different times in the life of a security. The questions are formed from a natural curiosity about the underlying principles that might be at work during the price discovery and information aggregation processes of markets. As will be illustrated in the body of the report, substantial progress is made toward this understanding for the special environments investigated.

The markets studied here have two major features. First, common knowledge exists about the periodic structure of information release to individuals and common knowledge exists about the underlying states of nature and the asset payoff given states. This common knowledge creates a framework through which the time path of the asset price might be understood by all agents in the market. Second, information about the underlying state is asymmetric across individuals and is released sequentially at the designated periods. In the end, complete information about the state and thus the asset payoff will exist if information held by the trading agents is aggregated, but such facts will not be known to any individual agent as private information. Thus, the fundamental issue of information aggregation presents itself.

Two broad questions organize the inquiry. (1) Does the time pattern of the asset prices reflect the expected value of the returns on the asset given the information available for aggregation and accumulation to date? In essence, the question is whether or not the central principle of fully revealing Rational Expectations can be observed at work in such a complex environment. A special case of this is the Black-Scholes model of options pricing where one of the assets traded is interpreted as an option and the information concerns the value of the underlying security. The reflection of expected value in the asset price is also a key principle associated with Rational Expectations as applied to all markets. As an empirical matter, the principle of Rational Expectations might not be expected to hold due to expectations about the future value of the asset, the possibility of speculative gains or even incomplete price adjustment that prevents past information to be properly integrated into the market. (2) What is the process through which information finds its way into the market?

\footnotetext{
${ }^{1}$ Department of Economics, University of Copenhagen (master's student) and Division of Humanities and Social Sciences, California Institute of Technology (visiting student).

${ }^{2}$ Università Ca' Foscari di Venezia and Division of Humanities and Social Sciences, California Institute of

Technology (visitor)

${ }^{3}$ Division of Humanities and Social Sciences, California Institute of Technology, Pasadena, CA 91125. cplott@hss.caltech.edu

${ }^{4}$ The financial support of the National Science Foundation and the Caltech Laboratory for Experimental Economics and Political Science are gratefully acknowledged. The authors have benefited from helpful comments of David Grether, Kerry Back, Ivana Komunjer and Pete Kyle. Of course, responsibility for errors resides with the authors.
} 
The "no trade" theorem resides at one end of the spectrum of theoretical possibilities. The distinction between informed traders and noise (uninformed) traders also exists together with competing theoretical principles about the types of actions each will take. The experiments permit a direct examination of the issues.

Rich theoretical and experimental literatures are focused on the nature of price discovery and information in markets. For the most part, the principles that support classical theory have proved themselves to be powerful tools in predicting and explaining experimental observations but the understanding those tools provide is by no means complete. A brief review of the experimental background will be useful and theoretical aspects are addressed in the section on models later in the paper. The experiments reported here involve an integration of different parts of the overall puzzles addressed in the literature: the details of the price discovery process, the role of time in that process, and the aggregation of bits and pieces of relevant information held by different agents. The approach has been from two perspectives. One is to explore the capacities of markets to perform as suggested by theory and the other is to explore the detailed mechanisms through which such capacities come into being. As will become apparent, this schizophrenic approach will be employed in this study as well.

Questions regarding the price discovery process itself have been a challenge since Vernon Smith's (1962) [51] demonstration of the operation of the laws of supply and demand. While the theoretical literature tends to assume the existence of a Walrasian auctioneer or market maker that functions along similar lines, for exceptions see Easley and Ledyard (1993) [21] and Plott and Turocy (1996) [47], the experimental literature contains greater focus on the details of how price adjustments might take place. It is well established that the operation of the laws is sensitive to the details of market organization and, in that regard, the most efficient of market making process is thought to be the multiple unit double auction $^{5}$, which was implemented in the markets studied here. The dynamics of the price discovery process in double auction markets are known to be related to the classical excess demand, Anderson, et. al., (2004) [2], and insights about the way that excess demand translates itself into prices are becoming identified, see Cason and Friedman $(2003,1996)$ [14, 15], Brewer, et. al. (2002) [10] and Asparouhova, et. al. (2003) [5], together with the types of orders that they may execute during the price discovery process, Bloomfield, et. al. (forthcoming) [8].

Time and assets impose particularly challenging features of behavior. That markets are capable of guiding price discovery over time along the lines suggested by theory is well known, Forsythe, et. al. (1982, 1984) [21, 22], and Friedman, et.al. (1984) [27]. However, speculation and other features of agent choices can intervene to produce bubbles and other forms of unexpected behaviors, Smith, et. al. (1988) [50], Abbink and Rockenbach (2004) [1]. Institutions thought to be important for immediate market "corrections" during the bubble periods, do not do so, but other instances in which individual behavior seems at odds with orderly market development are offset by the heterogeneity of agents, Kluger and Wyatt (2004) [33], Olivin and Rietz (2004) [40]. Bubbles themselves have been shown to be closely related to confusion on the part of agents, Lei, et. al. (2001) [35], which is a fact that

\footnotetext{
${ }^{5}$ This mechanism is development and tested in Gray and Plott (1990) [44] as a generalization of the one unit double auction studied by Smith (1962) [51]. The multiple unit double auction has been implemented in several elections exchanged systems including the Marketscape system employed here.
} 
will be used later. Thus, any study of markets in which time plays a central role must be prepared for the emergence of phenomena that are not predicted by classical principles. The same can be said about experiments with random variables. However, slight adjustments to classical models have successfully captured the variability.

That markets have the capacity to aggregate information has been well established since the discovery by Plott and Sunder $(1982,1988)[45,46]$. Aside from the fact of aggregation, they demonstrated important facts. The nature of aggregation is sensitive to the instruments in the market. (Plott 200, 2001) [42, 43]. In particular, if preferences are diverse the Arrow-Debreu securities are important but that is not the case if preferences are identical, or near so across agents. Furthermore, informed agents tend to be the first to place orders in the market, a fact that will become important later in this report. Subsequent research had replicated their findings, testing the sensitivity to the number of insiders, Watts (1993) [53] and Nöth and Weber (1999) [38] in addition to isolating the importance of experience and public knowledge of preferences under which information aggregation may and may not be expected, Forsythe and Lundholm (1990) [23], Ang and Schwarz (1985) [4]. As the number of states become expanded and the number of insiders become variable additional, bubble like phenomena, called mirages, begin to appear, Camerer and Weigelt (1990) [12]. The concept of a mirage will be important later as a tool to analyze the results reported here. The market architecture (Chen and Plott, 2002) [16], as well as the possibility of collusion among market makers, can have a dramatic impact on the ability of markets to aggregate information, Cason (2000) [13].

When time and information asymmetries are both present, such as they are in the experiments reported here, the total of complexities introduced above exist plus some additional matters. Copeland and Friedman (1987, 1991, 1992) [17, 18, 19] studied the effects of information arrival in a market with a single period showing that markets are sensitive to arrival but with mixed results regarding the capacity of market prices to fully reveal the information as is predicted by the fully revealing Rational Expectations model. More recently, Camerer, et. al. (1999) [11] have demonstrated the existence of "information traps" that can occur as a result of coordination and constraints such as cash constraints or no short sales constraints, that can result from information becoming available at different times or having relevance at different times. The concept of an information trap will be used in sections below.

\section{Market environment and information}

The particular environment was motivated by the structure of an option with a given strike price. Often the price of the underlying security is modeled as a random walk, with sequential information arriving about the price of the underlying security and thus the ultimate payoff of the option. Thus, each period the information arrives about whether or not the price of the underlying asset went up or down, thus making the ultimate value of the option go up or down. The issues center on how this complexity becomes incorporated into the asset price. 


\section{The asset structure: states and payoff}

Each session of the experiment is partitioned into periods and years. A year consists of three periods during which trading can take place. Figure 1 summarizes the time features of the environmental environment. All markets are for a single asset that pays a single dividend depending on the state of nature. There are four states of nature with associated dividends of 800, 600, 400 and 200. The determination of the state of nature was as if nature performed an independent draw each period eliminating one of the states with the most extreme values (the highest value or the lowest value) from those that have not previously been eliminated. From the point of view of a risk neutral agent, it is as though nature chose, with equal probability, the expected value of the state prior to the next period, beginning with a choice between 400 and 600. Due to the structure of the binomial tree depicted in Figure 1, the states 600 and 400 each have a probability of 3/8 while the states 800 and 200 each have a probability of $1 / 8$ of occurring. This occurs as the individual draws up and down in each period are equally likely.

\section{The information structure}

The tree represented in Figure 1 was common knowledge. Any information to be revealed was done at a node of the tree. The specific information revealed at nodes and who received it differed according to the experimental controls imposed. Two series of experiments were conducted, depending on the structure of the information that was revealed.

In Series One, the "Symmetric Information" case, all agents were uninformed at the beginning of a period about the draws for the upcoming period and knew that no-one else had private information about the period. At the end of the period the draw (up or down) was revealed in the form of a public announcement. Thus, the expected value of the asset prior to the draw for the period was public information. Accordingly, theory suggests a lack in the response to the actual movement until after the public announcement.

In Series Two, the "Asymmetric Information" case, a subset of one-third of the agents was given information about the draw in the upcoming period and could use this to eliminate one of the extremes. Thus, during the first period of a year the informed agents for that period would be able to eliminate either 800 or 200 from the possible states of nature. Each period a different set of agents received private information, so no agent was ever informed about more than one period.

Notice that although the asymmetric information structure is similar to the classical environment introduced in Plott and Sunder (1988) [46], major differences exist. In Plott and Sunder, half the subjects could eliminate one of three states and another half another one of the three possible states. Thus, no individual was perfectly informed, but the "market" was perfectly informed of the state and the market computation could be known by a simple pooling of the states that could be eliminated by individuals. In the experiments explored, the "market" is fully informed in the sense that a pooling of all individual private information (the content of the information and when the information arrived) would produce certain information about the state. However, the pooling is much more complex than in Plott and Sunder. Based on private information alone, each individual can eliminate only one of the 
two states ( 800 or 200). That is the pooling of states eliminated by private information removes only one or both of these two states but does not reveal the final state with certainty. For the final state to be computed, the timing of the private information must also be used. The significance of this fact is that the market must not only aggregate the information content, but must also aggregate the information timing if market performance along the lines of a fully revealing Rational Expectations equilibrium is to be observed.

In these experiments all agents are informationally small in the sense of Gul and Postlewaite (1992) [29]. Agents are informationally small, according to the Gul and Postlewaite concept if "...the incremental information of an agent given the information of everyone else ...(is).. small" 6 . In other words, the removal of the information held by a single individual does not change the aggregate of information in the market. Notice that in Series Two (Asymmetric Information) the condition is satisfied since three or more individuals have identical information. Removal of one of them leaves the aggregate of information in the market unchanged. The key point is that information smallness creates competition among the informed subjects and thereby competitive incentives to reveal their private information. As an aside, if two of the informed individuals are confused or do not participate for some reason, the remaining individual is no longer informationally small.

\section{Experimental Design and Procedures}

The main features of the experiments are summarized in Table 1. A total of five experimental sessions were conducted. They are indexed by the date of the experiment. Each of the five sessions lasted for two hours. The number of subjects in each session varied from nine to seventeen. Subjects were recruited from the Caltech student community with one exception. In 040506, three students from UCLA participated.

The basic setup for all experiments was the same. Caltech's web-based trading system Marketscape was used. It is a continuous, open book, double auction where information on the time series of all trades and orders in the book are public. Subjects place orders that are placed in the order book unless they can be crossed with orders that exist in the book from the other side of the market, in which case a trade or transaction is facilitated. As will be discussed in greater detail later, we define those who place orders that go into the order book as having placed a "limit order" and orders that are crossed immediately with limit orders from the other side of the market are defined as "market orders". From a technical point of view, however, the forms and language used in placing the orders is the same for both types of orders. ${ }^{7}$

All trading took place in an experimental currency called francs, where each franc was worth $\$ 0.001$. In every first period of a year, each subject was given an initial fixed endowment of 10 assets and 8000 francs, the latter as a loan that had to be repaid after each year. We did not allow subjects to go short in either asset or cash. After each year, the state of nature was revealed and earnings were recorded as number of assets times the dividend plus francs on hand minus the francs given as a loan.

\footnotetext{
${ }^{6}$ Gul and Postlewaite (1992), p. 1280 [29].

${ }^{7}$ During the experiment we had the trades and orders under surveillance. In 040527 , we discovered that two subjects combined to make three self-trades early in a period to manipulate prices. We announced publicly that these were self-trades and that it was not allowed.
} 
Once assembled at the Caltech Laboratory for Experimental Economics and Political Science, instructions were read out load and the use of Marketscape was briefly explained. The tree contained in Figure 1 was common knowledge and was presented to subjects along with the instructions that can be viewed in the appendix. During the experiment, the binomial tree in Figure 1 was drawn on the board for each period. In year 1 of all experimental series there was a public announcement of the actual draw from the previous round, the draw was written in the binomial tree after the announcement each period. In subsequent years, the information distributed at the nodes differed according to the experimental design discussed below. The market was opened for trading for a fixed length of time, five minutes per period, and was then closed in preparation for the upcoming period. If the period past was the third and thus final period of a year, the dividend was paid and subjects updated their earnings and waited for the first period of the next year.

Each experimental session followed an identical procedure. At the beginning of each session, a practice year was conducted as part of the instructions. The procedures used in the practice year were the same as those used in Series One (Symmetric Information). The purpose of the training session was to familiarize the subjects with the structure of the experiment and introduce them to the software used. There was no payment in the practice year and the data from these are not included in any of the results.

The first year of each of the five sessions was conducted under the conditions of Series One (Symmetric Information). Following the first year of each session, three years (three periods each) were conducted under the conditions of Series Two (Asymmetric Information). Thus, the aggregated data for all sessions consists of five years (fifteen periods) under the conditions of Series One (Symmetric Information) and fifteen years (fortyfive periods) under the conditions of Series Two (Asymmetric Information).

Belief information was collected after each period of Series Two (Asymmetric Information). After having seen their own private information for the previous period, conducted trades and observed the trades of others during the period, subjects were asked to place a bet on whether the draw of the previous period was up or down. The subjects had the choice of betting $\$ 0, \$ 0.25$ or $\$ 0.50$ at odds $2: 1$. These were collected after each year before the announcement of the state of nature and were added to the earnings at the end of the experiment. Both informed and uninformed were asked to place a bet. We used these to determine the beliefs and degree of confidence of the subjects. It is noteworthy, that no single subject made negative earnings on the betting.

\section{Economic Models and Theory}

In this section, competing models are outlined and applied to the experimental environment introduced above. The models provide tools through which patterns of data can be identified and interpreted.

Reflecting a diverse evolution, theory consists of a broad spectrum of models that range from those based on different principles of equilibrium to models that are very specialized and built on different axioms about individual behavior. Wee focus on two classes of models and inquire about the insights they provide about the behavior observed in the experimental markets. Equilibrium models have typically evolved through classical 
economics, sometimes modified by insights from game theory. Markets with imperfect competition in the information structure have evolved through the finance literature from a background of models specialized for applications in asset markets and markets reflecting organized securities markets.

\section{Equilibrium}

Three different equilibrium models are prominent in the literature. Two of these are included primarily for orientation and completeness of the discussion. The first of these three models, the No Trade Theorem, is important because much theory is developed from the hypothesis that it is reliable. It is important to notice that this theory predicts that no trade will take place in any of the markets studied here. The second of the three, The Fully Revealing Rational Expectation Equilibrium, is the central focus of the study. The last of the three models, the Private Information Equilibrium is important as a baseline against which one can compare information aggregation in markets. It is, in a sense, a compromise between the other two so it should be considered regardless of its role as a baseline.

Game Theory: The No Trade Theorem (NTT). The model predicts that no trade will take place.

Under the assumption of risk neutrality, the markets are a zero sum game; the asset has the same value to all parties as does the money. If information about the value of the asset is known to one party and not the other and this pattern of knowledge is public, then game theory predicts that no trade will take place due to the strategic position in which all agents find themselves. The basic principle is a No Trade Theorem that holds that no agent will trade with an agent with more information, and if both agents have the same information, there are no gains from trade. Thus, according to the model the system is at equilibrium when no trade takes place in either Series One (Symmetric Information) or Series Two (Asymmetric Information).

Fully Revealing Rational Expectations Equilibrium (RE). The fully revealing Rational Expectations equilibrium model holds that all information available to the market will be immediately incorporated into the price.

In Series One (Symmetric Information), markets are open for period one without any information about the state made available to the agents. They know only that the state is distributed as described in Section 2 and Section 3 above. Without additional information, the asset has an expected value of 500. Agents know that at the end of the period, one of the extremes states will be removed as a possibility and with this revelation the expected value will become either 400 or 600 with a 50:50 chance of each. Thus, the model predicts that prices will be at the expected value given previously announced draws starting at 500 in period 1 then moving to either 400 or 600 for period 2 and then moving up or down by 100 from there, depending on the announced draw.

In Series Two (Asymmetric Information), information about one event (the elimination of one of the extremes, 200 or 800 , as a possible value of the asset) is given to a subset of individual before the opening of period one. The information allows those with it to adjust the expected value of the asset to either 600 or 400 . The model holds that this information will be reflected by the price that emerges in period 1 . That is, the price will be 
either 600 or 400 during period 1. Before the opening of period 2, a different subset of agents is told which of the extremes that remains, the high or the low, can be removed. So, if 800 were announced as removed from possibility in period 1, the new information would reveal that either 600 or 200 can be removed as a possibility. If 200 was announced as removed from possibility in period 1 then in period 2 the new information, when combined with the information revealed in period 1 would allow either 800 or 400 to be removed as a possibility leaving the expected value given all information to be either 400 or 600 .

According to the model, prices in a period will be the expected value of the asset given all information that was available to the market at the start of the period.

Private Information Equilibrium (PI). The model holds that the price of the asset will reflect the maximum expected value based on the private information alone held by agents.

It is important to note that private information in Series Two (Asymmetric Information) has two components, a time component and a state elimination component. The state elimination component allows the holder to eliminate only one of the two states 800 or 200 in the absence of any other information. In the absence of the information that became available in the earlier period, the expected value based on private information alone is either 400 or 600 and nothing else, regardless of the time of the information. The information becomes more powerful given the information that was from the previous period due to the conditioning on the time component. For example, agents with information in the third period know the state with certainty if they know the information available in the first two periods.

In Series One (Symmetric Information), the predictions of the PI and the Rational Expectations are the same. In Series Two (Asymmetric Information), the model predicts only prices of 400 or 600 , which are the only expected values that can be calculated from private information alone. Unless budget constraints intervene, the price will be the expected value of the agent with the highest expected value that exists in the market at the time. For example, if the private information is up in the first period, a price of 600 will emerge for the period, pushed there as the informed agents buy from the uninformed. However, if the private information is down, the price will be 500, as the uninformed buy from the informed. If the information is up for each of the three periods, the price will be 600 and if the information is down for each of the three periods, the price will be 400 and get there through a path of 500 for the first and second periods.

\section{Information Micro Structure: Competition, Imperfect Competition and Information Revelation}

A class of models initiated by Kyle (1985, 1989) [34, 35] and modified and generalized by Foster and Viswanathan (1996) [25], Dutta and Madhavan (1993) [20] and Back $(2000,2004)[6,7]$ extends the theory to central aspects of a price discovery process. The models themselves rest on forms of imperfect competition in the revelation of information to the market. Traders can anticipate the market reaction to the information they reveal and thus, in light of possible competition from other traders who have the same or similar information, trade with the realization that they will have an impact. The principle at work is monopoly or monopolistic competition in which information is the valuable resource 
that receives the rents from imperfect competition and the rents accrue to informed traders. In a manner similar to the way that the distribution of demand and supply functions shape the outcome in a world of imperfect competition, the distribution of information shapes the outcome in a market with a potential for information aggregation.

Application of the micro structure models to the experimental environments here requires interpretations. First, the micro structure models distinguish between limit orders and markets orders. In the experimental environment, limit orders are those that reside in the book. Market orders, though technically limit orders, never enter the book because they are crossed immediately with the other side of the market. That is, a market order is the acceptance of an offer that was first made by the other side of the market. Thus for purposes of analysis, the offer expressed in an order is defined as a limit order and the acceptance, the order that subsequently creates a contract, is defined as a market order. Second, the micro structure models rest on assumptions of three types of traders: noise traders, informed traders and market makers. By contrast, the experimental markets have only two types of traders, informed and uniformed. In the experimental markets, there is no special "market maker". Thus, the behavior of the informed and the uniformed humans in the experimental markets are represented, respectively, by the informed and the noise traders of the model.

In the models, the noise traders typically have neither inside information nor pricing power and express their orders as market orders and exist only to prevent the model from becoming stuck at a no trade equilibrium. Market makers, who are in the model to supply liquidity have no inside information but have some pricing power expressed in the terms of limit orders. The behavior of insiders has been associated with both market orders and limit orders. On one hand limit orders, the submission of a function to the market, can be viewed as revealing more information, as well as providing an option to an agent willing to trade against the order. Thus, limit orders might be avoided by those with inside information. On the other hand, the limit order suggests a bit of market power and the existence of monopoly rents resulting from pricing as opposed to rents to information. Exactly why an insider would chose one form of order over another is not made clear in terms of theory and indeed it might make no difference at all in terms of existing models. As an attempt to capture this open question a behavioral postulate is developed as the following axiom.

The Informed Trader Competitive Hypothesis (ITCH): The behavior of insiders and non insiders are indistinguishable in terms of timing and in terms of the use of limit orders and market orders.

At the other extreme, is a case of a monopoly insider who has inside information and knows that no other trader has the information and anticipates the impact of orders on market prices. Of course, the behavioral concept is readily extended to perfect collusion among a set of insiders. Kyle (1989) [35] develops the key model and demonstrates that some of the monopolist's information never gets revealed to the market, so fully revealing Rational Expectations prices never emerge. The basic behavioral postulate is captured by the following axiom.

The Informed Trader Monopoly Hypothesis (ITMH): The informed trader(s) submit limit orders that anticipate the information revelation effect on market price. The information is 
revealed slowly over time and the ultimate prices fall short of the fully revealing Rational Expectations.

The case of multiple insiders who have the same (or similar) information was studied by Foster and Viswanathan (1996) [25] and generalized by Back, Cao, and Willard (2000) [7]. Trading patterns in these models exhibit competition among the insiders. ${ }^{8}$ Intuitively, the first to trade does so before the information rents are dissipated by the information revealed in the orders of competitors. Drawn by profits, the insiders thus "race" to trade. That idea produces the following hypothesis about the behavior of insiders.

The Informed Trader Rat Race Hypothesis (ITRRH): Informed traders enter the market early in the trading period. Over time, the information becomes fully incorporated (when all insiders have identical information) and fully revealing Rational Expectations are approached.

A comment made now, with the benefit of the results to come, might serve to emphasize the delicate features of theory. The rush of insiders to trade could be in anticipation of the price decreases that would result from the trading of other insiders. Thus, not only do existing profit potentials stimulate trading by the insiders, so also is the realization that the opportunity will be temporary, due to the oligopolistic responses of other insiders. Since the uniformed have no incentive to rush, there will be no liquidity on the other side of the market that would facilitate successful market orders by the insiders. Thus, competition among the insiders must take place in the form of limit orders as opposed to market orders. Furthermore, it is only by placing orders that are more aggressive than those of others will an insider have the order exposed to the other side of the market. Thus competition for access to the other side becomes an important force. How that property becomes represented in the model is not always clear and whether or not such intuition follows directly from existing models seems to be subject to interpretation.

A final postulate that has been used in this literature deals with the propensity of information to accumulate over time in the sense that in each period the new information is added to the old. For the most part, the literature deals with environments in which the information is produced by some stationary stochastic process. In the experiments, that is not the case. When agents have information that is produced by different processes operating at different points in time one can imagine insiders exhibiting a tendency to wait until the end of the year to reveal what they know. Or similarly one can imagine insiders using a strategy design to mislead and then profit from mislead future traders. The following hypothesis is used to guide an inquiry about such possibilities.

The Accumulated Information Hypothesis: Newly arrived information becomes evaluated conditional on the past information as reflected in past prices. Traders rely on information in past market prices and not only on their own information about the past when making current decisions.

The behavioral literature contains many theories that suggest that the models above might not work. For example, a "disposition effect" claims that investors have a bias towards selling former winners rather than losers, which empirically suggests that subjects

\footnotetext{
${ }^{8}$ For an extension and review see Back (2004 [6]).
} 
will have difficulty selling assets that have increased in price in the previous period. Bad news would not become reflected in price if it follows good news. The literature also suggests a prominence of mental accounting, which is a tendency to compartmentalize different types of events and worry about fluctuations in each one separately. Over time, behaviour may not reflect the integration of experiences or reflect any overall learning and, if that is the case, information might not accumulate as suggested by the hypothesis.

\section{Measurement and Econometric Methods}

The data were explored with different econometric tools to control for robustness of our stated results. We report two models and will refer to them as the AE Model and the AR1 Model. From time to time throughout the paper, we will note if the choice between these two models might make a difference in the interpretation of the data. For the most part, they tell us exactly the same thing.

\section{The Ashenfelter-El Gamal Model}

To assess the degree to which prices are converging to theoretical prediction, we use the following model attributed to Orley Ashenfelter and Mahmoud El Gamal (AE model) by Noussair, Plott and Riezman (1995) [39].

$$
\begin{aligned}
& P_{i, t}=\frac{1}{t} \sum_{i=1}^{i=k} d_{1, i} D_{i}+\frac{t-1}{t} \sum_{i=1}^{i=k} d_{2, i} D_{i}+u_{i, t} \\
& u_{i, t}=\gamma \cdot u_{i, t-1}+\varepsilon_{i, t} \\
& \varepsilon_{i, t} \approx N(0, \sigma)
\end{aligned}
$$

where $t$ is the time, $D_{1}$ are dummy variables, $d_{1, i}$ and $d_{2, i}$ are the coefficients to estimate and $e_{i, t}$ is an i.i.d error term. Variables $D_{i}$ take value 1 in period $i, 0$ otherwise.

In this model, the estimated $d_{1, i}$ is a measure of the starting price (when $t=1$ all the weight is on the first term on the right side of above equation) as well as $\mathrm{d}_{2, \mathrm{i}}$ is an estimate of the limit of the price time series (for $\mathrm{t}$ ? 8 all the weight is on the second term on the right side of above equation). For convenience, we will refer to this estimated limit as the AE eq. price. The concept of time used in the estimation of the equations was number of trades. Other concepts of time, such as seconds, in periods of 30 seconds, and number of actions (bids, asks and trades) were tested and number of trades seemed to be the best for an overall integration of results.

\section{The AR1 Model}

In addition to the AE model, we use the following autoregressive model of order 1:

$$
\begin{aligned}
P_{i, t} & =\sum_{i=1}^{i=k} d_{i} D_{i}+\rho P_{t-1}+u_{i, t} \\
u_{i, t} & =\gamma \cdot u_{i, t-1}+\varepsilon_{i, t} \\
\varepsilon_{i, t} & \approx N(0, \sigma)
\end{aligned}
$$


where $\mathrm{D}_{1}$ are dummy variables defined as in the previous model, $\mathrm{t}$ is the time and $\mathrm{e}_{\mathrm{i}, \mathrm{t}}$ is an i.i.d error term. With the estimated coefficients, we can compute the estimated limit of the time series as the stationary price of the autoregressive model in the following way:

$$
\overline{P_{i}}=\frac{d_{i}}{1-\rho}
$$

We will refer to this as the AR1 eq price. Finally, to check if the prices converge to prices predicted by theory under the hypothesis of information aggregation, we compute intervals of confidence (at $95 \%$ level) of the estimated stationary price, AR1 eq. price, and check if the theoretical price is within this interval or out. To build these intervals, we need the variance of $\bar{P}$ that we compute using the delta method.

To estimate both models, we use the Cochrane-Orcutt transformed regression estimator that permits consistent estimation in the presence of first-order-serially-correlated residuals. In detail, we use a search method to estimate the value of the autoregressive coefficient ? that minimizes the sum of squared errors of the transformed equation.

\section{Results}

All periods of all experiments were studied with both the AE model and the AR1 model and the estimates from the two models are contained in Table 2. An AR2 model was also used but none of the conclusions below are changed if it is used. The table contains estimates of the convergence price, the Rational Expectations price prediction, and the Rational Expectations predicted movement from the previous period. Periods are classified as a full convergence to the Rational Expectations price, a bubble, a mirage or a period of no movement. Confidence intervals and other measurements are also included in the table. For the most part, the AE model and the AR1 model paint very similar pictures of the behaviour of the markets but there are slight differences as will be illustrated in the pages that follow and we want to make sure that they reader does not become confused.

The results are partitioned into two subsections. The first section addresses market performance and model accuracy using traditional market measures in addition to the new data on beliefs produced by the betting data. The fundamental message of the section is that price data and belief data strongly support the Rational Expectations class of theories but there are notable exceptions. Both bubbles and mirages can be observed in these markets and the analysis is focused in part on their definition and characterisation. The second section turns to the process through which information aggregation occurs in markets.

\section{Market Performance and Model Accuracy}

The time series of all years of Series One (Symmetric Information) for all experiments are shown in Figure 2 in relation to the expected value of the asset (fifteen periods). Similarly the time series for all periods of all years of all experiments of Series Two Asymmetric Information) are shown in Figure 3 in relation to the expected value of the asset given the aggregate of private information held by individuals, which is the prediction of the fully revealing Rational Expectations model (forty- five periods). 
The first question posed is whether or not the markets studied here have a tendency to converge to the fully revealing Rational Expectations equilibrium. Do prices tend to reflect the aggregate of information available to all participants to date? The two different series are reviewed. Result 1 deals with Series One (Symmetric Information). These markets are of interest as a baseline of assessing the capacity of markets to adjust to new information. Verification of such capacities is needed because of reports of bubbles, speculation, confusion and other phenomena that can intervene during market adjustments. Result 2 deals with the Series Two (Asymmetric Information). In Series Two (Asymmetric Information) the information aggregation becomes important.

RESULT 1. In Series One (Symmetric Information), prices converge to the fully revealing Rational Expectations equilibrium (the risk neutral expected value given all information available to the market).

\section{SUPPORT.}

The price is converging to the expected value at the $95 \%$ confidence level in 10 of the 15 periods when the AE model is used. This can be observed in Table 2 where the column conv. indicates whether the price has converged (marked with a 1 ) or not (marked with a 0 ). The number of periods is 11 out of 15 when the AR1 model is used and the number of periods for which either the AE or the AR1 model is not significantly different is 11 out of 15 periods. The two models thus give almost the same result. Three of the four periods in which the difference is not significant are first periods and this failure of significance is with no doubt related to the very small variance of prices. Measuring how the direction of prices change in response to new information gives even stronger support for the Rational Expectations model. Using this criterion (columns emp. mov. in table 2) in the Series One (Symmetric Information) markets, the movement was correct in all cases and significant in all 10 instances for the AR1 model and 9 out of 10 for the AE model. Only 040513-1-2 ${ }^{9}$ is not significant, but still correct in the AE model. $\nabla$

RESULT 2. In Series Two (Asymmetric Information), the Rational Expectations is much better than the alternative Private Information model. In most periods, prices either move in the direction of or converge close to the fully revealing Rational Expectations equilibrium.

\section{SUPPORT.}

We skip any detailed comparisons between the Private Information model and the fully revealing Rational Expectations model since it is an exercise in the obvious. We turn instead, to an evaluation of the fully revealing Rational Expectations model. The data are contained in Table 2. Viewing intra period transactions with the AE model, the markets attain the fully revealing Rational Expectations expected value in 28 out of the 45 periods in Series Two (Asymmetric Information, column conv. is a 1 in Table 2). Using the AR1 model the markets attain the fully revealing Rational Expectations in 24 out of 45 periods in Series Two (Asymmetric Information, column conv. is a 1 in Table 2). These are where the result is significant using a confidence interval of $95 \%$ for both models. Viewed another way, in 31

\footnotetext{
${ }^{9}$ Throughout we will use the notation session-year-period when denoting a particular period or year in a certain session.
} 
of 45 periods either the AE or the AR1 model says that the data are converging to the fully revealing Rational Expectations equilibrium in Series Two (Asymmetric Information).

A second method of testing asks if the markets move in the direction of the fully revealing Rational Expectations equilibrium given the new information that is made available to the market. The tests ask: (i) is the movement of prices in the direction of the fully revealing Rational Expectations equilibrium and (ii) is the difference in price significantly different from the prices in the previous period. Basically, the model requires that a statistically significant movement exists in the direction predicted by the model. In the first period, the convention asks that the movement be different from the expected value of 500, then plus or minus 100 depending on the movement being up or down. The condition is met in 35 out of 45 periods using the AE model, and in 38 out of 45 periods using the AR1 model. The null hypothesis that the direction of movements is equally likely is rejected at confidence levels of $1 \% . \nabla$

Clear exceptions exist to the Rational Expectations convergence process reported in Result 2. These require examination and in doing so we define two different types of phenomena. A bubble is identified as a period in which the market moves in a direction opposite to the direction indicated by the newly arrived information and simultaneously that the direction is opposite to the direction dictated by the aggregation of all information available to the market. A mirage is equilibration to the wrong equilibrium and we adopt the convention that the final trades in a period are not on or very near the right equilibrium, a phenomenon that is symptomatic but might be insufficient to show up in the statistics. A mirage is typically consistent with a (potential) Rational Expectations of previous prices, which have moved near a wrong state so the movements in the mirage periods are in the "right" direction. Basically, a mirage is most easily identified when there was a bubble somewhere in the past. The third phenomena of note are periods of non-movement of prices from one period to the next. It is similar to a sluggish price adjustment sometimes observed in markets. These periods are 040513-3-2 and 040527-3-2. For purpose of analysis, we group periods into "bubble periods", "mirage periods" and "non-bubble-mirage periods". 10

RESULT 3. Bubbles and Mirages can be observed in the markets.

\section{SUPPORT.}

As identified in Table 2 (by viewing the column bubble where a 1 appears), three periods of bubbles can be identified in the markets. These are 040506-3-1, 040506-4-1 and 040527-2-2. It should be noted that in 040527-2-2, the movement using the AR1 model is consistent with our definition of a bubble, but it is not significant at a $95 \%$ level. We choose to still treat it as a bubble as it is supported by the AE model, where it is a bubble and significant at a 95\% level. In all of the three cases with bubbles, the market moved against the information contained in the just arrived private information and in all cases the market moved against the direction dictated by all information available to the market. In this respect, it should be noticed that in session 040506 the just arrived information was all information in the market because the bubbles occurred in the first period. The event in

\footnotetext{
${ }^{10}$ We also studied separately the periods that tightly converged to the fully revealing Rational Expectations equilibrium. Splitting these periods out for study produced no additional results and changed none of the results that follow.
} 
session 040527 is different, however, because the bubble occurred in the second period and thus first period information existed in addition to the second period information.

Using Table 2 (by viewing the column mirage where a 1 appears), four examples of mirages exist in the data using the AR1 model ${ }^{11}$. 040506-3-2, 040506-3-3 both adjust to levels that would be consistent with their fully revealing Rational Expectations equilibria, had the information available in the first period been accurately reflected in the market. 040506-4-2 is similarly a convergence to the "wrong" price due to an earlier incorrect pricing of the asset. The phenomenon can be seen again in 040527-2-3 in which the incorrect adjustment in 040527-2-2 causes 040527-2-3 to converge to a wrong equilibrium but is a correct fully revealing Rational Expectations equilibrium given prices in 040527-2-2. $\nabla$

The next result, Result 4, provides a connection with price discovery and beliefs as contained in patterns of betting. Recall that individuals had the option of placing bets of various sizes on the changes of expected state (up or down) as reflected in the market responses to the information that was placed in the market in the previous periods. These bets are interpreted as beliefs. In particular, the size of the bet is interpreted as reflecting confidence in a belief. Confidence is defined as the percentage of actual betting amount relative to the maximum amount possible to bet by uniformed individuals. Accordingly, if all uninformed bet $\$ 0.50$, the confidence is $100 \%$. Likewise, if all uninformed choose to bet $\$ 0$, the confidence is $0 \%$.

Figure 4 contains summaries of the data used in Result 4 stated below. Figure 4 shows the percentage of bets that were placed on the correct state and the degree of confidence in those bets. The data are from the bubble periods, the mirage periods and the remaining periods as a group. For analytical purposes, only the bets placed by the uninformed are considered as all bets placed by informed were correct and placed on the full amount of $\$ 0.50$.

RESULT 4. Ex post belief formations of the uninformed are consistent with a Rational Expectations interpretation of market prices. (i) Information is aggregated (except in periods with bubbles) as reflected in correct and strongly held beliefs. (ii) In periods with bubbles, beliefs are incorrect, but held with strong confidence. (iii) Beliefs lack some confidence during the mirage periods as compared to other periods.

\section{SUPPORT.}

Part (i). Of the uniformed people $84 \%$ place bets on the correct state is 307 out of a total number of 354 made by the uninformed in all five sessions. However, the proportion of correct bets differs dramatically across sessions and periods according to the existence of a bubble or not. In 040505 , only 2 out of 78 bets were wrong. Overall, 18 out of 20 bets made by the uninformed in the three bubble periods were wrong. If the bubble periods are

\footnotetext{
${ }^{11}$ The classification of periods into mirages is somewhat sensitive to the econometric model used to estimate price movements. The classification we use in the support is a result of the AR1 model. If we use the Ashenfelter-El Gamal model periods 040404-3-2 and 040506-2-2 will be added as mirages and 040506-3-3 is not classified as a mirage. Such additions would be questionable because they do reach the Rational Expectations equilibrium on the final trades and the deletion would be questionable because prices move in the direction of two Rational Expectations equilibria but do not fully adjust to either, but remain a long dis tance from the actual Rational Expectations for the period.
} 
removed from the overall sample, only 29 of 334 bets are placed on the wrong draw. Basically, less than 1 in $10(8.7 \%)$ of the bets placed by uninformed people was wrong for the non bubble periods, but during a bubble almost all are wrong $(90 \%)$. A test on the difference between the two proportions of error $(8.7 \%$ in non bubble periods and $90 \%$ in the bubble periods) leads to a rejection of the hypothesis of no difference of the proportions at a $1 \%$ level of confidence.

Part (ii). In the three periods where a bubble is observed (040506-3-1, 040506-4-1 and 040527-2-2), the average betting confidence is $85 \%$. So there is no evidence in the betting behavior that the market senses that it is in a bubble. Contrary, subjects are actually placing stronger bets ex post during a bubble than in other periods.

Part (iii). A simple average (not weighted by the number of subjects) of the betting confidence overall is $80 \%$. In the four periods where a mirage is observed (040506-3-2, 040506-3-3, 040506-4-2 and 040527-2-3) the average betting confidence is 73\%. This is reflected in Figure 4. This suggests that the market senses something wrong in mirage periods. There is thus an interesting difference in the betting behavior compared to the bubble periods which we will turn our attention to next. $\nabla$

The Part (ii) of the above result have particularly strong implications since the bets are made ex post to the period and all bids, asks and trades have been observed. When the market is truly wrong as in the case bubble, it has no idea that it is wrong. This belief does not reveal a bubble. By contract, the relatively low level of confidence could be an indication that a mirage is generally unstable whereas a bubble, at least in the short run, is stable since the uninformed do not detect it.

Natural questions to pose are related to experience and learning. We have no special models with which to explore the possibilities but do offer an observation. As stated in the observation below confidence in beliefs become stronger with experience.

OBSERVATION 1. The level of bets increases slightly in the later periods.

\section{SUPPORT.}

There is an increase in the amounts that the uninformed bet. It is accompanied by an increase in confidence of bets as depicted in Figure 5. If the data behind this figure are aggregated, a simple average confidence (not weighted by the number of subjects in each session) rises from $73 \%$ in the first year of all Series Two (Asymmetric Information) to $78 \%$ in the following year and $89 \%$ in the last year. There is thus an indication that the strength of beliefs may increase with experience. $\nabla$

Together Result 4 and Observation 1 indicate that the Accumulated Information Hypothesis receives support in these markets. Beliefs are based on market price and are accurate. The information accumulates across time. Individuals add information contained in past prices to the newly arrived private information confidence in the information increases with time. The process of balancing private information with the information contained in prices as implied by the hypothesis seems to be taking place.

\section{The Process of Information Aggregation (The Market Micro-Structure)}


This section begins with a statement of a possibly important discovery that we will call The Fundamental Coordination Principle of Information Transfer in Competitive Markets. The fact that markets have the capacity to solve complex problems of aggregation motivates a question of how it happens. Our attempts to answer the question lead to the discovery. ${ }^{12}$ Result 5 is a statement of the fundamental principle and Result 6 demonstrates that bubbles and mirages are related to the instances in which it fails.

RESULT 5. The Fundamental Coordination Principle of Information Transfer in Competitive Markets. Informed traders initiate action early in a market period and do so by placing limit orders. The uniformed enter after the informed and do so with market orders as opposed to limit orders. Such tendencies tend to dissipate later in the period.

\section{SUPPORT}

Measurement in support of Result is restricted to actual contracts as opposed to tenders that do not make a market. Support for Result 5 can be seen in Figure 6. In the aggregate, it is not the case that the information of the trader dictates whether a limit order or market order is tendered. This is defined by using the ratio of contracts with a limit order placed by an informed subject to contracts with a limit order placed by an uninformed subject. Overall, this ratio is 0.69 (see Table 3). But if we look at the micro structure, an interesting fact appears and supports Result 5. The overall ratio starts out being high in the first minute (1.34 on average, see the overall line in Figure 5 and minute 1 in Table 3) of a period, then drops to 0.69 and 0.73 by the second and third minute and decreases to near the expected number of 0.50 by the fourth minute $(0.49)$ and 0.59 in period five. The expected ratio of 0.50 appears as there are app. 1/3 informed and 2/3 uninformed subjects in the Series Two (Asymmetric Information) case. $\nabla$

Result 5 provides a clear connection between observation and theory. ${ }^{13}$ The next observation summarizes that connection.

\footnotetext{
${ }^{12}$ An instant of the principle is clearly evident in the first experiments dealing with information aggregation by Plott and Sunder (1982) [45] who reported that informed traders were in markets early that the information they held tended to be revealed by the bids and asks.

${ }^{13}$ The central property identified in the result was first reported in Plott and Sunder (1982) [45] (see their p.687 and Table 8). On the surface, Result 5 might appear to be inconsistent with results reported in Bloomfield, et.al. (forthcoming) [8] but that is not the case. Markets in Bloomfield, et.al. implemented a feature of some financial markets in which the market opening is preceded by a pre-market market. Thus, an opportunity existed for informed traders to submit limit orders. No doubt, this period of "cheap talk" contributed to the price discovery process just as it is supposed to do. Thus the limit order activity took place in the pre-market market. While the overall pattern of results seems consistent in the light of this difference, other features of the Bloomfield, et.al. paper could serve to create differences. In particular, the time periods were very short relative to experience in experimental markets and expected volume, especially in light of the fact that in their software, orders were restricted to single units only, which is known to increase the time required for markets to properly clear. Short time periods have long been identified as a source of alteration to market convergence processes (Plott, 1983) [41]. The one unit per order constraint could also have implications for the interaction between traders and the book, due to queues at a price in the book and the time priority of execution. Also important is the fact that the Bloomfield, et.al. markets had only two insiders thereby creating incentives to collude that often appear as market signals in bids and asks and would cloud any analysis of instrument use. Finally, the use of penalties as an incentive for liquidity trades creates the equivalent of a short sale squeeze that is known to have the capacity to disrupt the ordinary price discovery process, King, et. al. (1990) [32], Porter and Smith (1995) [49]. In spite
} 
Observation 2. Among the models of market micro structure as applied to these markets, the ITRRH receives support while ITCH and ITMH do not.

The failure of the Fundamental Coordination Principle can be directly associated with the instances and periods in which the fully revealing Rational Expectations model fails in the data. We will define Coordination Reversals to be instances in which the fundamental coordination principle does not hold. That is, coordination reversals are instances in which uninformed behave as informed by entering the market early, placing limit orders. ${ }^{14}$ The following result summarizes the data.

RESULT 6: The Coordination Reversal phenomenon is present in periods where the fully revealing Rational Expectations equilibrium is not reached. That is, during non-bubblemirage periods the tendency is for the informed to place limit orders in the first trades but during the bubble and mirage periods the uninformed place limit orders in the first trades.

\section{SUPPORT:}

The following results are supported by data summarized in Table 4, Table 5 and can be viewed graphically in Figure 6. The result can be seen by comparing the ratio of limit orders in the trades during each minute of the periods where the fully revealing Rational Expectations equilibrium is reached as compared to the periods where there is either a bubble or a mirage. Using Table 4 for the non-bubble-mirage periods, the ratio of limit orders placed by informed subjects to limit orders placed by uninformed subjects is 1.56 in the first minute and 0.71 in the second minute $(0.76,0.55$ and 0.67 in the third, fourth and fifth minutes respectively). By comparison, using Table 5 (the column ratio for informed to uninformed) for the bubble and mirage periods, the ratio of contracts with informed people placing the limit order to uniformed is 0.56 in the first minute and 0.57 in the second minute $(0.56,0.18$ and 0.19 in the third, fourth and fifth minutes respectively). Thus, during the bubble and mirage periods, the informed traders are less aggressive, revealing less relative to uniformed agents, during the first minutes of trading, as compared to the non-bubble-mirage periods. In a statistical sense, we get three supportive results that are significant at a $95 \%$ confidence level. (1) There is a tendency for informed to trade with limit orders in the first minute of non-bubble-mirage periods, whereas there is a tendency for uninformed to trade with limit orders in bubble and mirage periods. This can be seen from Tables 4 and 5 . In periods with bubbles or mirages, the Chi2 test rejects the null hypothesis of independence between time and the proportion of limit orders by informed or uniformed agents (See Table 5). The interpretation is that the proportion of insiders doesn't depend on time in the bubble and mirage periods. Contrary, the Chi 2 test for independence is rejected in Table 4. The interpretation is that the proportion of insiders does depend on time in the non-bubble-mirage periods, meaning that they trade with limit orders early. (2) It is supported by the notion of the probit test in Table 6 (part b). This shows a negative (and significantly different from zero) correlation with time in the non-bubble-mirage periods of minus 0.0020365 . The

of the differences, the Bloomfield, et al., data suggest that the Fundamental Coordinating Principle operated in their markets as well as ours.

${ }^{14}$ The property of coordination failures appear to be similar to phenomenon identified in cascades (Hung and Plott (2001) [31]). Individuals add information revealed by the actions of others to their own information but do so with less weight then suggested by Bayes Law. When the information is misleading, the information aggregated is itself wrong. 
interpretation is that the more time that goes by, the less likely is an informed to trade using limit orders in the non-bubble-mirage periods. (3) By the second minute the difference in the bubble and mirage contra non-bubble-mirage periods is no longer significant. This is shown in Table 7 that shows the statistical test on the difference of the bubble or mirage and nonbubble-mirage periods as illustrated by the p-value of 0.038698 in the first minute as appears in the last column.

These statistical tests emphasize that in the non-bubble-mirage periods, information is revealed in limit orders early. As mentioned earlier this corresponds to the findings of Plott and Sunder (1982) [45] (see their Table 8 and discussion at p.687). $\nabla$

We do not know if coordination failures are a cause or a symptom of the failure of the fully revealing Rational Expectations to develop. Two other phenomena tend to be present as well during the bubble periods. Information traps ${ }^{15}$ are situations in which some agent is unable to profit on private information due to a lack of funds (a cash constraint and no borrowing power) and/or a lack of units to sell (a no short sale constraint). In such events, the information held by the agent is "trapped" in the sense that the market process permits no avenue through which the privately held information can enter the market. Another phenomenon is confusion or misunderstanding. In the context of the experiments studied here, confusion is present when a person does not act on (or acts contrary to) private information when it is profitable and when the person is not constrained to do otherwise.

RESULT 7: In all three instances of bubbles, information traps possibly in connection with confusion contribute to the creation of the bubble.

\section{SUPPORT.}

In 040506-3-1, two of the three informed people sold out \#123 and \#129 and the third person who was informed was confused, \# 126, selling one unit and holding nine but betting correctly with confidence (i.e. the full amount). So, the system was in a combination of confusion and an information trap. Two of the three informed people had no more units to sell and thus could not get the information into the market while the third was confused. The confusion of \#126, as opposed to some sort of expectation, is documented through behavior in other periods. Specifically in 040506-2-3, this subject decreased holdings on positive information, again betting correctly the full amount.

In 040506-4-1, all three informed people had sold out (3 122, \#125 and \# 128) so the system was in an information trap.

In 040527-2-2, one of the informed spends everything and is at the boundary so this person is trapped (\#122 buys up and is caught on the cash constraint). The other two informed individuals make no trades at all, but they do bet properly (\# 125, \#128). The two "confused" people exhibit unusual behaviors in other parts of the experiment. In 040527-3-3, \#125 should sell but does nothing and in 040527-4-1 should buy and does not change holdings. In 040527-3-3, \#128 should sell, but buys heavily and 040527-4-1 should buy and does so. $\nabla$

\footnotetext{
${ }^{15}$ The concept of an information trap is introduced by Camerer, Noeth, Plott and Weber (1999) [11].
} 


\section{Conclusions}

Two important lessons emerge from the experiments and analysis. The first is that assets can integrate information that arrives over time. The price of the option is observed adjusting substantially as predicted by a Rational Expectations model. The second and perhaps the most important lesson of the research is the picture of how information finds its way into a market together with the circumstances that accompany the failure of information aggregation. The picture rests on the discovery (Result 5) of a behavioral property that we call The Fundamental Coordination Principle of Information Transfer in Competitive Markets. The phenomenon is clearly suggested by the Informed Trader 'Rat Race' Hypothesis (ITRRH). However, the details of the underlying forces at work are still a mystery. Two candidate theories are evident at the moment. One is in the spirit of the market micro structure literature and holds that imperfect competition among informed traders is at the heart of the process. The other rests on informationally small agents (or agents who act as if they are informationally small), who do not attempt to hide their private information but nevertheless rush to trade and take advantage of the profits suggested by their private information and in doing so collectively reveal what the ynow. Regardless of the underlying economics, failure of the operation of the principle, accompanied or caused by confused agents and buttressed by information traps account for incomplete or incorrect information transfer and aggregation failure with resulting bubbles and mirages.

The picture begins with the fact that there is little if any support for the No Trade Theorem. It is included here only for completeness. A long history of experimental research in economics and finance demonstrates a natural tendency toward trade. The theoretical invention of "noise" traders is a natural tool with which to capture this inexplicable tendency, thereby preventing the model from becoming "stuck" at a no trade equilibrium. Separate incentives for agents to provide "liquidity" are not really necessary in markets because people naturally bring a propensity to trade with them. The picture continues with the important fact that a tendency exists for markets to collect and aggregate dispersed information, even when the information enters the market at different times. The experiments provide much support for the equilibration principles that support a class of Rational Expectations models of markets and in particular demonstrate the relevance of the time structure of options pricing models. That fact is the clear implication of Result 1 and Result 2. However, bubbles and mirages in which the information transfer is incorrect or incomplete can occur (Result 3). Interestingly, the manifestation of Rational Expectations principles and the related importance of beliefs receive support from the application of a new methodology for collecting beliefs (Result 4).

The process of information transfer and aggregation follows an identifiable path dependent, pattern. The first to arrive in a market in time and in terms of commitment are those with the information. That is the Fundamental Coordination Principle of Information Transfer in Competitive Markets. The informed traders place limit orders early in the period and the uninformed traders, the "noise" traders, place market orders that cross with the informed traders (Result 5). While in these markets the informed traders are informationally small, they behave much like competitors that compete with other informed traders for access to the uniformed and in doing so reveal what they know. While the theoretical themes from the market microstructure literature do capture major patterns of what happens in the markets, the data exhibit clear cases in which the information does not become aggregated. 
Both bubbles and mirages can be observed. Bubbles exist when the current information accepted by the market is_completely wrong and mirages exist when current information is accepted correctly but all information available is not, causing the markets to converge to the "wrong" equilibrium. Because the failures of information aggregation are exceptions in the markets we study an opportunity to study the process of failure presented itself. Such study reveals three different phenomena. The first we call Coordination Reversals in which the uninformed are the first in the market. This can happen extremely rapidly, within the first few seconds of a market. The second is confusion exhibited when subjects either fail to act on their information at all or act in a manner inconsistent with their own interest. The third are information traps, when occur when constraints of one form or another prevent an agent from acting on information. These are studied in Result 6 and Result 7.

Once information is introduced into the market there is a "contagion" or "cascade" effect as the information implicit in the first few trades finds its way to the uninformed traders as a whole. The behavior of informed and uninformed become indistinguishable. Learning then proceeds in a naturally understandable manner in which experience plays a role in organizing the natural and orderly introduction and transformation of information in the market.

The process discovered would seem to depend heavily on the competitive nature of the markets. The lack of information monopoly would also seem to be important together with public information about the nature of potential insider information. Finally, the process would seem to be very sensitive to the details of the market organization and the public information about the arrival of information. The study of the implications of these variables must await another day. 


\section{Appendix}

\section{A.1. Instructions}

\section{General}

This is an experiment in the economics of market decision making. The instructions are simple, and if you follow them carefully and make good decisions, you might earn a considerable amount of money which will be paid to you in cash.

In this experiment, we are going to conduct a market in which you will be a participant in a sequence of market years. Each year consists of three periods. The length of each period will be 5 minutes unless told otherwise. You will be given a number of certificates that each will pay a liquidation dividend at the end of each year. A certificate is thus a claim on a payment at the end of each year. The markets for certificates have a one year (=three periods) life. The dividend depends on the independent draws in the individual periods. The attached information sheet will help determine the value to you of any decision you might make. You are not to reveal this information to anyone. It is your own private information.

\section{Specific Instructions}

The type of currency used in this market is francs. All trading and earnings will be in terms of francs. Each franc is worth _ 0.001 _ dollars to you (i.e. _1000_ francs $=\$ \$_{-} 1 \_$). Do not reveal this number to anyone. At the end of the experiment your francs will be converted to dollars at this rate, and you will be paid in dollars. Notice that the more francs you earn, the more dollars you will earn.

At the beginning of a year, you will be given _10_ certificates and _8000_francs (as a loan). Your profits come from two sources - from collecting liquidation dividends on all certificates you hold at the end of "Period 3" and from buying and selling certificates. During each market year, you are free to purchase or sell as many certificates as you wish.

\section{Determination of Draws}

The dividend you receive from the certificates you hold depends on the draws of the three periods. In each of the three periods, the draw can be either up (U) or down (D). The draw of each period will be random and determined before each year begins. The draw will be made public after the corresponding period. The draws were picked from a random table, which can be inspected by anyone after the experiment. In all periods, the draws $U$ and $D$ are equally likely.

To sum up - you will start every year (Period 1) with an initial endowment of certificates and an amount of francs given to you as a loan. You may sell the certificates if you wish, you may hold them, or you may buy more. If you hold a certificate at the end of the third period you receive the liquidation dividend $X$. Your initial holding at the beginning of Period 2 (and thereafter Period 3 etc.) is determined by your final holdings in Period 1 (and thereafter Period 2 etc.), i.e. your certificates and cash are carried over from period to period. At the end of a year, you are free to keep all dividends plus your francs on hand minus the francs 
given to you as a loan at the beginning of a year. These are your profits for the year. No short selling is allowed, i.e. you can only sell as many certificates as you have at any given time. Communication not related to the trading is not allowed. 


\section{References}

1. Abbink, Klaus and Bettina Rockenbach (March 2004): "Option Pricing by Students and Professional Traders: A Behavioural Investigation"

2. Anderson, Christopher M., Charles R. Plott, Ken-Ichi Shimomura and Sander Granat (April 2004): "Global Instability in Experimental General Equilibrium: The Scarf Example," Journal of Economic Theory, 115, 2, pp. 209-249.

3. Ang and Schwartz (1992): "The formation and control of asset bubbles: An experimental study", Working Paper.

4. Ang and Schwartz (1985): "Risk Aversion and Information Structure: An Experimental Study of Price Variability in the Securities Markets", The Journal of Finance, 11, No. 3: 825-844.

5. Asparouhova, Elena, Peter Bossaerts and Charles R. Plott (2003): "Excess demand and equilibration in multi- security financial markets: the empirical evidence", Journal of Financial Markets, 6:1-21.

6. Back, K. (2004): "Incomplete and Asymmetric Information in Asset Pricing Theory", in Stochastic Methods in Finance, M. Fritelli and W. Runggaldier, eds., SpringerVerlag, pp. 1-21.

7. Back, K., H. Cao and G. Willard (2000): "Imperfect Competition Among Informed Traders", Journal of Finance, 55: 2117-2155.

8. Bloomfield, R., M. O'Hara and G. Saar, "The 'Make or Take' Decision in an Electronic Market: Evidence on the Evolution of Liquidity" Journal of Financial Economics (forthcoming).

9. Bossaerts, Peter and Charles R. Plott (2002): "The CAPM in thin experimental financial markets", Journal of Economic Dynamics and Control, 26: 1093-1112.

10. Brewer, Paul J., Maria Huang, Brad Nelson and Charles R. Plott (2002): "On the Behavioral Foundations of the Law of Supply and Demand: Human Convergence and Robot Randomness, Experimental Economics 5: 179-208.

11. Camerer, Colin F. Markus Nöth, Charles R. Plott, and Martin Weber, "Information Aggregation in Experimental Asset Markets: Traps and Misaligned Beliefs," Social Science Working Paper no. 1060. Pasadena: California Institute of Technology, April 1999. Under revision.

12. Camerer, Colin and Keith Weigelt (1990): "Information mirages in experimental asset markets", Working Paper, University of Pennsylvania.

13. Cason, Timothy N. (2000): "The Opportunity for Conspiracy in Asset Markets Organized with Dealer Intermediaries", Review of Financial Studies, 13, No.22: 385416. 
14. Cason, Timothy N. and Daniel Friedman (1996): "Price formation in double auction markets", Journal of Economic Dynamics and Control, 20: 1307-1337.

15. Cason, Timothy N. and Daniel Friedman (2003): "Buyer search and price dispersion: a laboratory study", Journal of Economic Theory, 112: 232-260.

16. Chen, Kay-Yut and Charles R. Plott, "Information Aggregation Mechanisms: Concept, Design and Field Implementation,” Social Science Working Paper no. 1131. Pasadena: California Institute of Technology. March 2002. Submitted for publication.

17. Copeland, Thomas E. and Daniel Friedman(1987): "The Effect of Sequential Information Arrival on Asset Prices: An Experimental Study", The Journal of Finance, 43, No. 3: 763-797.

18. Copeland, Thomas E. and Daniel Friedman(1991): "Partial Revelation of Information in Experimental Asset Markets", The Journal of Finance, 46, No. 1:265295.

19. Copeland, Thomas E. and Daniel Friedman (1992): "The Market Value of Information: Some Experimental Results", Journal of Business, 65, No. 2:241-266.

20. Dutta, Prajit K. and Ananth Madhavan (1992): "Price Continuity and Insider Trading”, Rochester Center for Economic Research, Working Paper No. 338.

21. Easley, David and John O. Ledyard (1993): "Theories of Price Formation in Double Auction Auctions," in D. Friedman and J. Rust (Eds), The Double Auction Market: Institutions, Theories an Evidence, 63-98.

22. Forsythe, Robert, Thomas R. Palfrey and Charles R. Plott (1982): "Asset valuation in an experimental market", Econometrica, 50:537-568.

23. Forsythe, Robert, Thomas R. Palfrey and Charles R. Plott (1984): "Futures markets and informational efficiency: A laboratory examination", Journal of Finance, 39: 955981.

24. Forsythe, Robert and Russell J. Lundholm (1990): "Information aggregation in an experimental market", Econometrica, 58:309-347.

25. Foster, Douglas F. and S. Viswanathan (1996): "Strategic Trading When Agents Forecast the Forecast of Others", The Journal of Finance, LI, No. 4: 1437-1478.

26. Friedman, Daniel and Joseph Ostroy (1995): "Competitively in Auction Markets: An Experimental and Theoretical Investigation”, The Economic Journal, No. 105, 22-53.

27. Friedman, Harrison and Salmon (1984): "The informational efficiency of experimental asset markets", Journal of political Economy, 92, 349-408. 
28. Guarnaschelli, Serena, Anthony M. Kwasnika and Charles R. Plott (2003):

"Information Aggregation in Double Auctions: Rational Expectations and the Winner's Curse,', Information Systems Frontiers 5:1:61-75.

29. Gul, F. and A. Postlewaite (1992): “Asymptotic Efficiency in Large Economies with Asymmetric Information,” Econometrica 60, pp 1273-92.

30. Hayek, F.A.(1945): "The Use of Knowledge in Society", American Economic Review 35, 519-30.

31. Hung, Angela A. , and Charles R. Plott (2001): "Information Cascades: Replication and an Extension to Majority Rule and Conformity Rewarding Institutions," American Economic Review, 91, no. 5: 1508-20.

32. King, Ronald R., Vernon L. Smith, Arlington W. Williams and Mark Van Boening (1990): "The robustness of bubbles and crashes in experimental stock markets", Journal of Economic Behavior and Organization.

33. Kluger, B.D. and S.B. Wyatt (June 1994): "Are Judgment Errors Reflected in Market Prices and Allocations? Experimental Evidence Based on the Monty Hall Problem" Journal of Finance, 59, No. 3: 969-998(30)

34. Kyle, Albert S. (1985): “Continuous Auctions and Insider Trading”, Econometrica, 53, No. 6: 1315-1335.

35. Kyle, Albert S. (1989): "Informed Speculation with Imperfect Competition", Review of Economic Studies, 56: 317-356.

36. Lei, Vivian, Charles N. Noussair and Charles R. Plott (July 2001): "Non-Speculative Bubbles in Experimental Asset Markets: Lack of Common Knowledge of Rationality vs. Actual Irrationality, Econometrica 69, no. 4: 831-59.

37. Mailath, G.J., and A. Postlewaite (1990): “Asymmetric Information Bargaining Problems with Many Agents," Review of Economic Studies, 57: 351-67.

38. Noth, Markus and Martin Weber (1999): "Insider Detection in Experimental Asset Markets".

39. Noussair, Charles N., Charles R. Plott and Raymond G. Riezman (1995): “ An Experimental Investigation of the Patterns of International Trade", The American Economic Review, 85, No. 3: 462-491.

40. Oliven, Kenneth and Thomas A. Rietz(March 2004): "Suckers are Born, but Markets are Made: Individual Rationality, Arbitrage and Market Efficiency on an Electronic Futures Market", Management Science, 50, 336-351.

41. Plott, Charles R. (March 1983): "Externalities and Corrective Policies in Experimental Markets.” Economic Journal 93, :106-127. 
42. Plott, Charles R. (2000): "Markets as Information Gathering Tools." Southern Economic Journal 67(1),:1-15.

43. Plott, Charles R., "Equilibrium, Equilibration, Information and Multiple Markets: From Basic Science to Institutional Design.” Nobel Symposium on Behavioral and Experimental Economics, Stockholm, Sweden. December 4, 2001.

44. Plott, Charles R. and Peter Gray (1990): "The Multiple Unit Double Auction" Journal of Economic Behavior and Organization 13 :245-58.

45. Plott, Charles R. and Shyam Sunder (1982): "Efficiency of Experimental Security Markets with Insider Information: An Application of RationalExpectations Models, Journal of Political Economy, 90, No. 4: 663-698.

46. Plott, Charles R. and Shyam Sunder (1988): "Rational Expectations and the Aggregation of Diverse Information in Laboratory Security Markets", Econometrica, 56, No. 5: 1085-1118.

47. Plott, Charles R. and Theodore L. Turocy III (1996): "Intertemporal Speculation Under Uncertain Future Demand: Experimental Results", Understanding Strategic Interaction- Essays in Honor of Reinhard Selten, W. Albers, W. Guth, P Hammerstein, B. Moldovanu and E. Van Damme (eds) Springer- Verlag, 475-93.

48. Plott, Charles R., J. Wit and W. C. Yang (2003): "Parimutuel Betting Markets as Information Aggregation Devices: Experimental Results," Economic Theory 22 :31151.

49. Porter, David and Smith, Vernon L. (1995): "Futures Contracting and Dividend Uncertainty in Experimental Asset Markets," The Journal of Business, 68, No. 4.

50. Smith, V., G. A. Suchanek and A. W. Williams (1988): "Bubbles, Crashes and Endogenous Expectations in Experimental Spot Asset Markets", Econometrica 56: 119-151.

51. Smith, Vernon (1962): “An Experimental Study of Competitive Market Behavior”, Journal of Political Economy 70: 111-137.

52. Sunder, Shyam (1992): "Market for information: Experimental evidence", Econometrica, 60:667-695.

53. Watts, Susan (1993): 'Private information, prices, asset allocation and profits: Further experimental evidence. In research In Experimental Economics, Vol. 5, Mark Isaac, editor, Greenwich, Conn: JAI Press. 
Figure 1: Time Structure of Periods for Information Revelation and Outcome Determination in an Experimental Year

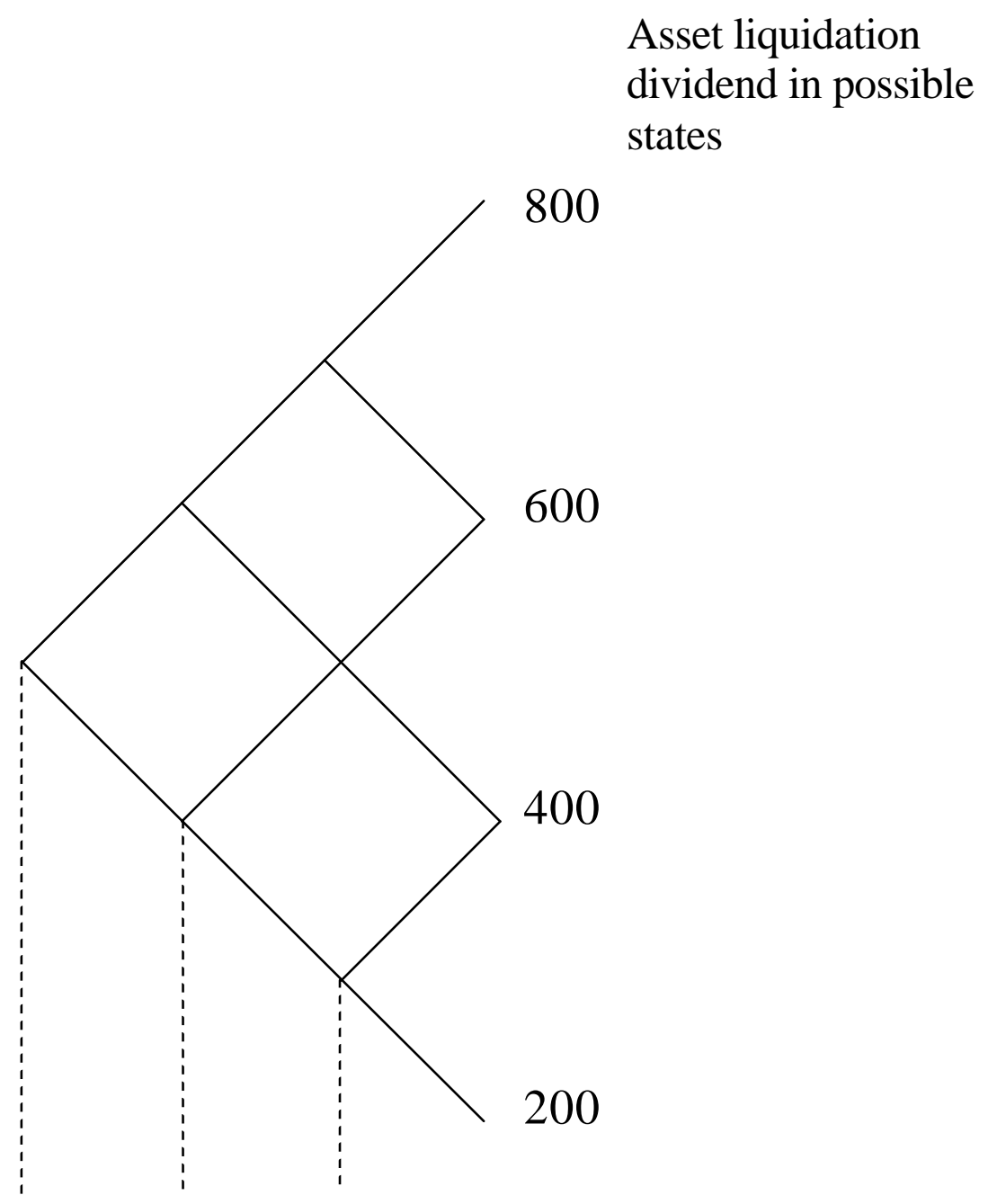

Period 1 Period 2 Period 3 
FIGURE 2: SYMMETRIC INFORMATION PERIODS, FIRST YEAR ALL EXPERIMENTS, TRADING PRICE AND RATIONAL EXPECTATIONS PREDICTED PRICES

$040505-1$

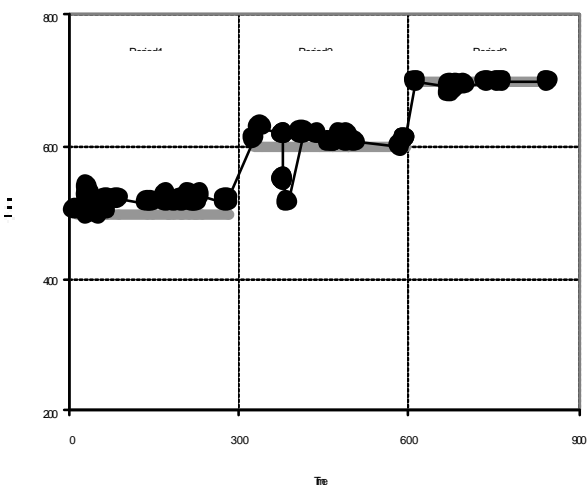

$040513-1$

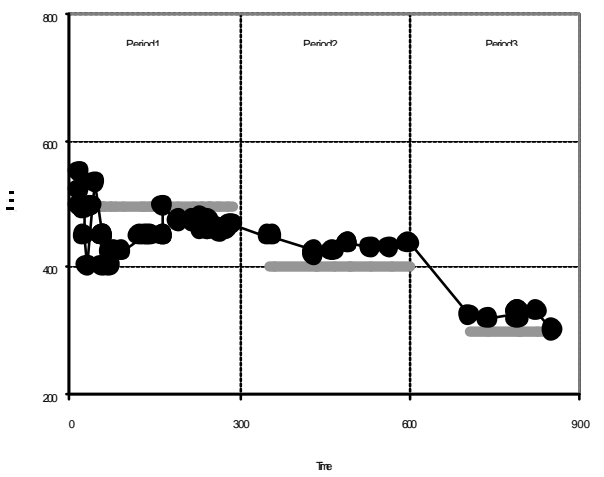

$040527-1$

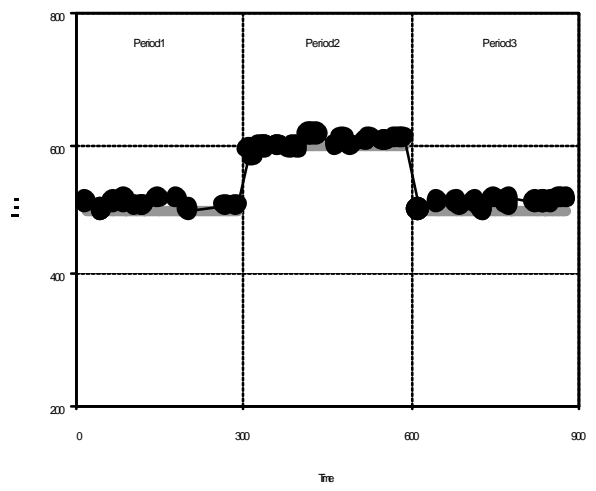

$040506-1$

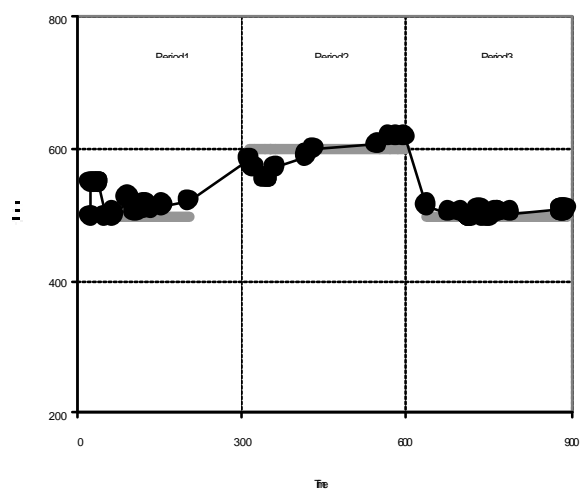

$040524-1$

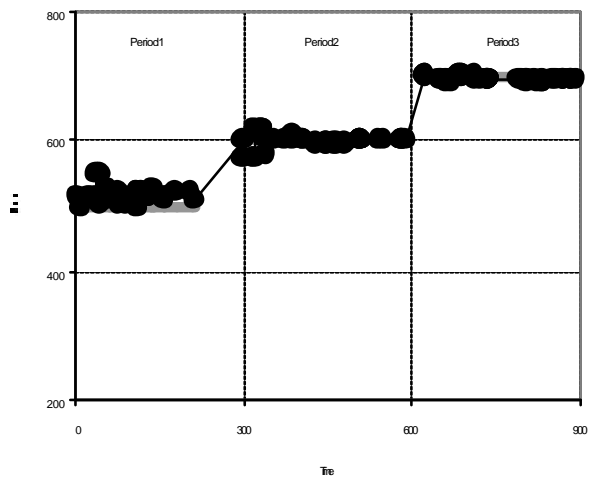


FIGURE 3: PRICE TIME SERIES, AND RATIONAL EXPECTATIONS PREDICTED PRICES, AS YMMETRIC INFORMATION, ALL PERIODS, ALL

$040505-2$

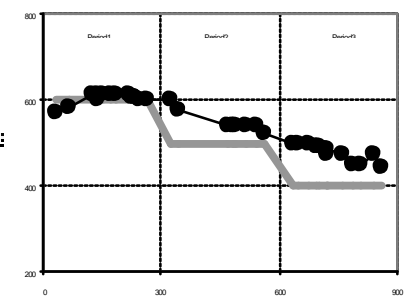

$040506-2$

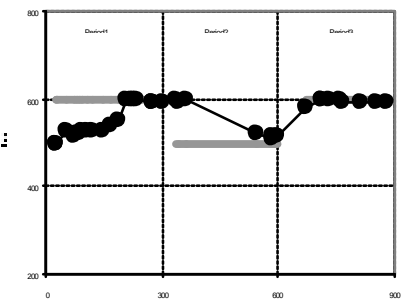

$040513-2$

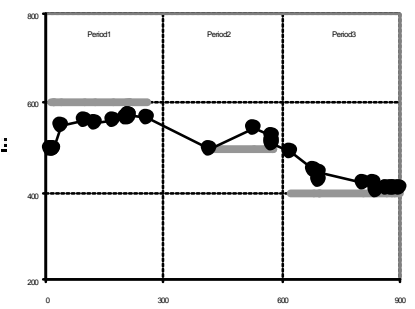

$040524-2$

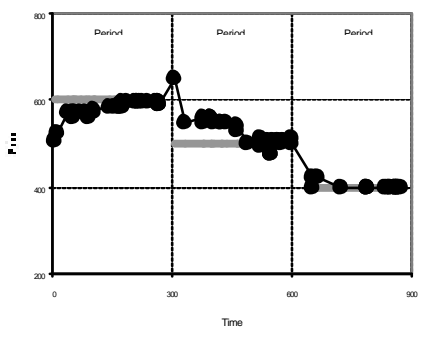

040527 - 2

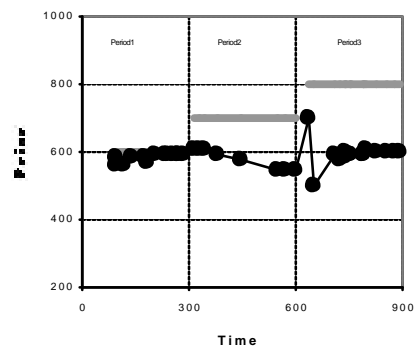

$040505-3$

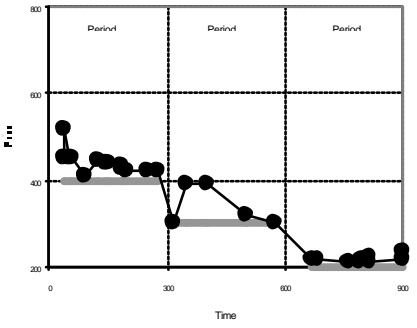

040506 - 3

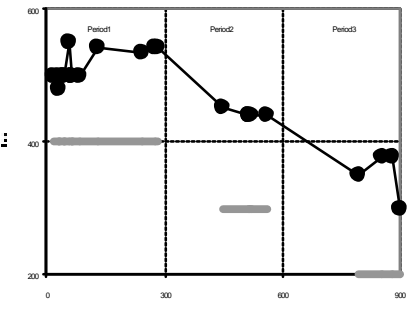

$040513-3$

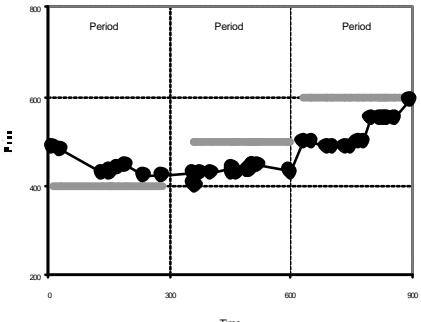

040524-3

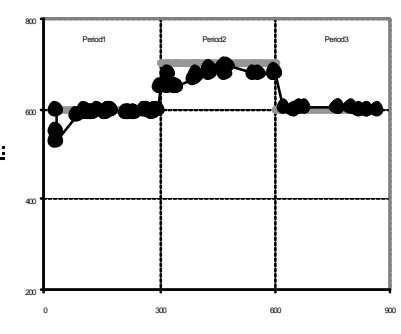

$040527-3$

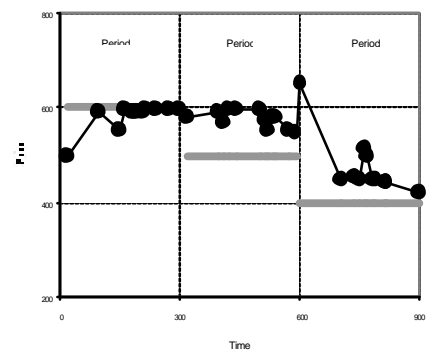

$040505-4$

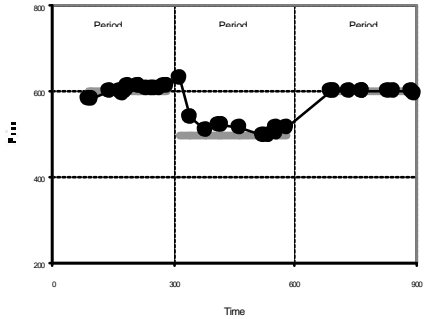

$040506-4$

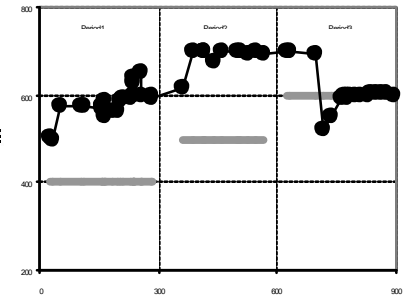

040513 - 4

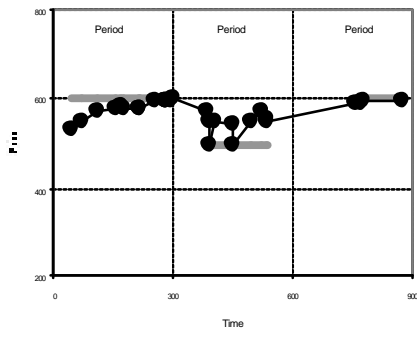

040524-3

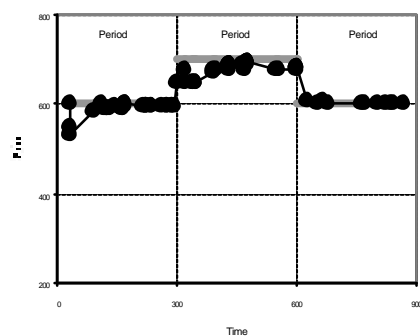

040527- 4

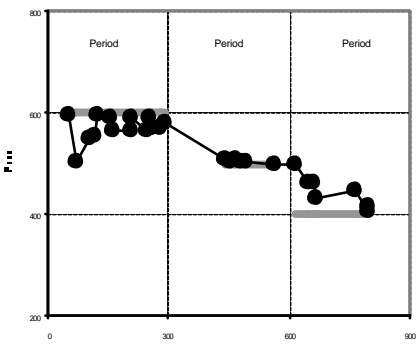


Figure 4: Average Percentage of Bets Made on the Correct State and the Average Size of Bets as a Percent of the Maximum

Possible(Confidence)

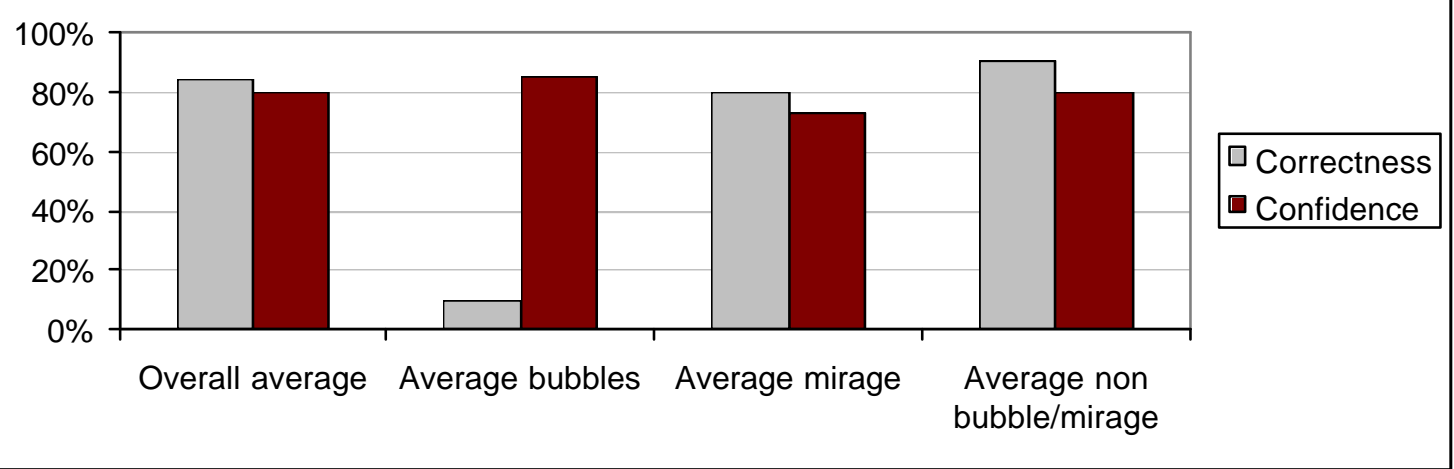




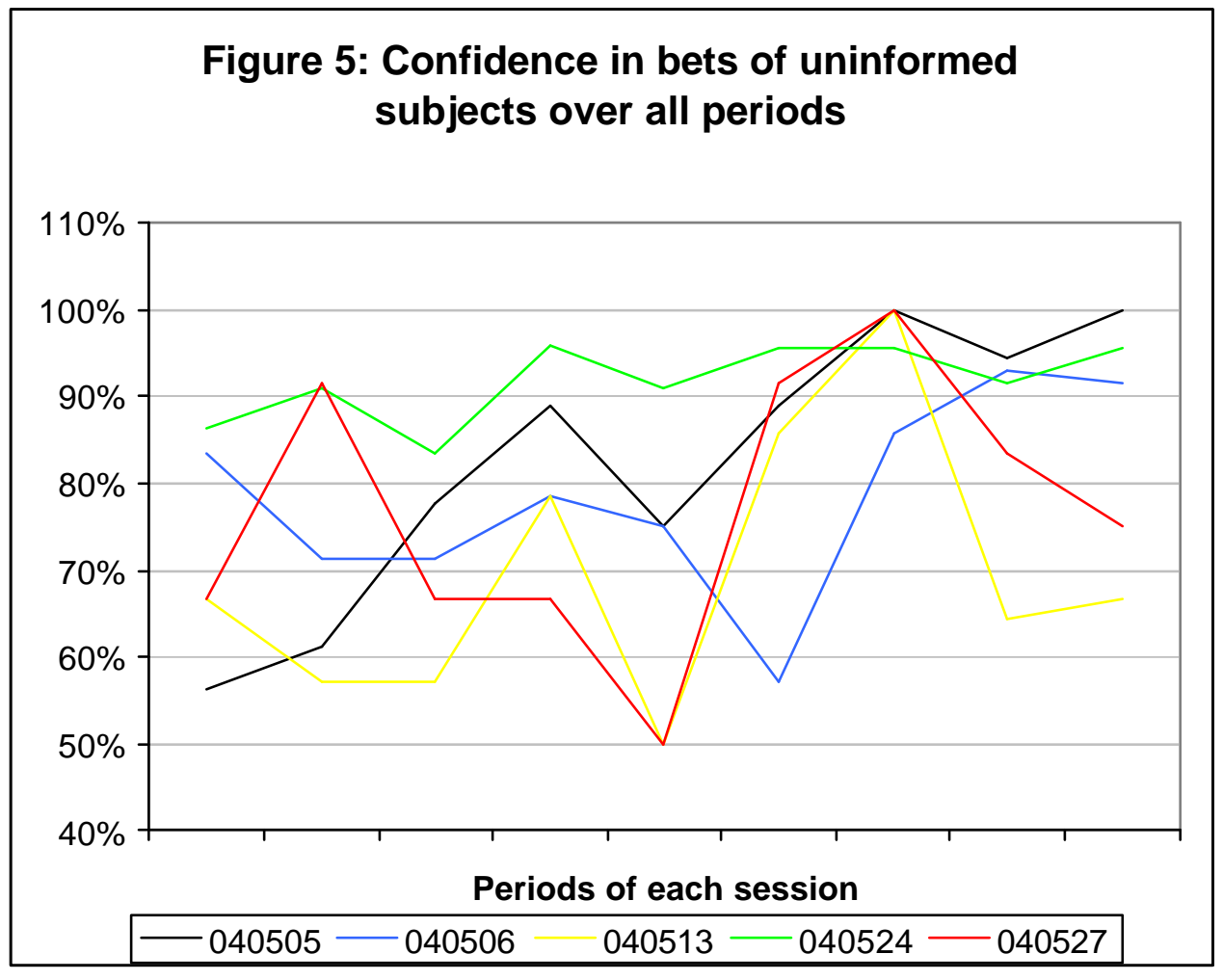


Figure 6: Ratio of informed to uninformed placing limit orders in each minute (aggregated)

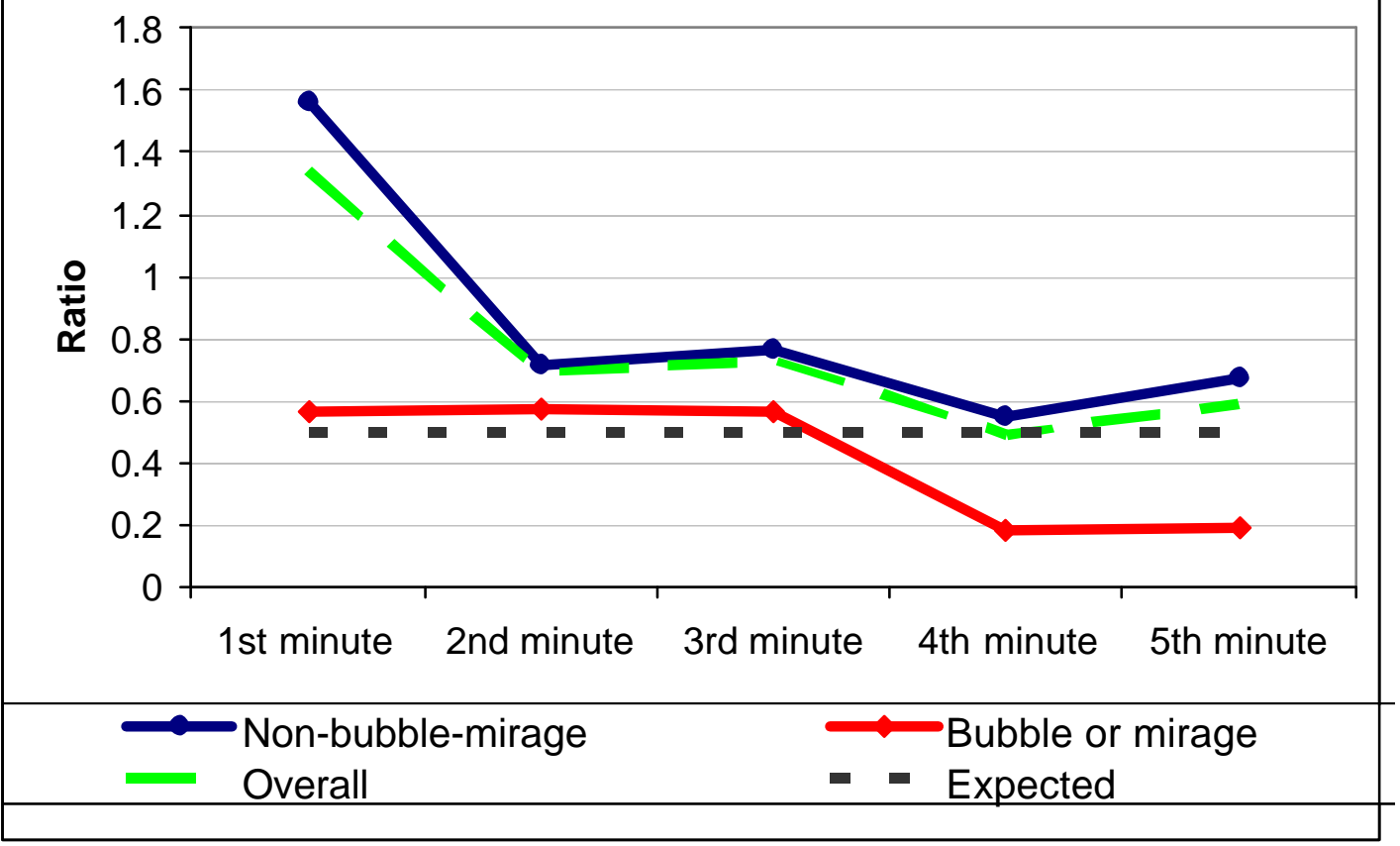


Table: 1: Experimental Conditions and Parameters

\begin{tabular}{llllllll}
\hline Experiment & Location & $\begin{array}{l}\text { Number } \\
\text { of } \\
\text { subjects }\end{array}$ & $\begin{array}{l}\text { Asset } \\
\text { endow } \\
\text { ments }\end{array}$ & $\begin{array}{l}\text { Cash } \\
\text { endow } \\
\text { ments }\end{array}$ & Series & Exchange rate & Duration \\
\hline 040504 & Caltech & 13 & 10 & 8000 & One and Two & 1000 francs $=\$ 1$ & 2 hours \\
040506 & Caltech & 10 & 10 & 8000 & One and Two & 1000 francs $=\$ 1$ & 2 hours \\
040513 & Caltech & 10 & 10 & 8000 & One and Two & 1000 francs $=\$ 1$ & 2 hours \\
040524 & Caltech & 17 & 10 & 8000 & One and Two & 1000 francs $=\$ 1$ & 2 hours \\
040527 & Caltech & 9 & 10 & 8000 & One and Two & 1000 francs $=\$ 1$ & 2 hours \\
\hline
\end{tabular}


Table 2 Parameter Estimates and Tests from AE Model and the AR1 Model

\begin{tabular}{|c|c|c|c|c|c|c|c|c|c|c|c|c|c|c|c|c|c|c|c|c|}
\hline \multirow{2}{*}{\multicolumn{3}{|c|}{ session-year-period }} & \multirow{2}{*}{\multicolumn{2}{|c|}{$\begin{array}{l}\text { expected } \\
\text { value th. } \\
\text { R.E.theory mov. }\end{array}$}} & \multicolumn{8}{|c|}{ AE eq price } & \multicolumn{8}{|c|}{ AR1 eq price } \\
\hline & & & & & \multirow{2}{*}{$\begin{array}{c}\begin{array}{c}\text { estimated } \\
\text { price }\end{array} \\
516.2\end{array}$} & \multicolumn{2}{|c|}{$\begin{array}{c}95 \% \\
\text { confidence } \\
\text { interval }\end{array}$} & \multirow{2}{*}{$\frac{\text { conv. }^{\mathrm{b}}}{0}$} & \multirow[t]{2}{*}{$\begin{array}{l}\text { emp.c } \\
\text { mov. }\end{array}$} & \multirow[t]{2}{*}{ bubble $^{d}$} & \multirow[t]{2}{*}{ mirage $^{e}$} & \multirow[t]{2}{*}{ no mov ${ }^{f}$} & \multirow{2}{*}{$\begin{array}{c}\begin{array}{c}\text { Estimated } \\
\text { price }\end{array} \\
516.9\end{array}$} & \multicolumn{2}{|c|}{$\begin{array}{c}95 \% \\
\text { confidence } \\
\text { interval }\end{array}$} & \multirow{2}{*}{$\begin{array}{c}\text { conv. } \\
0\end{array}$} & \multirow[t]{2}{*}{$\begin{array}{l}\text { emp. } \\
\text { mov. }\end{array}$} & \multirow[t]{2}{*}{ bubble } & \multirow[t]{2}{*}{ mirage } & \multirow[t]{2}{*}{$\begin{array}{c}\text { no } \\
\text { mov }\end{array}$} \\
\hline \multirow[t]{12}{*}{040505} & & 1 & 500 & & & 504.1 & 528.3 & & & & & & & 503.7 & 530 & & & & & \\
\hline & 1 & 2 & 600 & 100 & 601.6 & 587.1 & 616.1 & 1 & 85.4 & 0 & 0 & 0 & 598 & 583.3 & 612.7 & 1 & 81.1 & 0 & 0 & 0 \\
\hline & & 3 & 700 & 100 & 704.3 & 674.3 & 734.3 & 1 & 102.7 & 0 & 0 & 0 & 694.2 & 671.5 & 716.9 & 1 & 96.2 & 0 & 0 & 0 \\
\hline & & 1 & 600 & 100 & 612.3 & 591.2 & 633.4 & 1 & 112.3 & 0 & 0 & 0 & 610.8 & 592.2 & 629.3 & 1 & 110.8 & 0 & 0 & 0 \\
\hline & 2 & 2 & 500 & -100 & 513.9 & 474.9 & 552.9 & 1 & -98.4 & 0 & 0 & 0 & 525.7 & 499.3 & 552 & 1 & -85.1 & 0 & 0 & 0 \\
\hline & & 3 & 400 & -100 & 442 & 417.4 & 466.7 & 0 & -71.9 & 0 & 0 & 0 & 465.8 & 445.5 & 486.2 & 0 & -59.9 & 0 & 0 & 0 \\
\hline & & 1 & 400 & -100 & 397.5 & 374.8 & 420.2 & 1 & -102.5 & 0 & 0 & 0 & 422.6 & 403.1 & 442.2 & 0 & -77.4 & 0 & 0 & 0 \\
\hline & 3 & 2 & 300 & -100 & 157.2 & 81.3 & 233.1 & 0 & -240.3 & 0 & 1 & 0 & 303.4 & 265.6 & 341.2 & 1 & -119.2 & 0 & 0 & 0 \\
\hline & & 3 & 200 & -100 & 230.5 & 196.7 & 264.4 & 1 & 73.3 & 0 & 0 & 1 & 222.4 & 198.1 & 246.7 & 1 & -81 & 0 & 0 & 0 \\
\hline & & 1 & 600 & 100 & 613.1 & 596.4 & 629.7 & 1 & 113.1 & 0 & 0 & 0 & 607.4 & 591.4 & 623.5 & 1 & 107.4 & 0 & 0 & 0 \\
\hline & 4 & 2 & 500 & -100 & 507.6 & 480.6 & 534.6 & 1 & -105.5 & 0 & 0 & 0 & 506.4 & 485 & 527.8 & 1 & -101 & 0 & 0 & 0 \\
\hline & & 3 & 600 & 100 & 596.1 & 562.2 & 629.9 & 1 & 88.5 & 0 & 0 & 0 & 597.5 & 573.2 & 621.7 & 1 & 91.1 & 0 & 0 & 0 \\
\hline \multirow[t]{3}{*}{040506} & & 1 & 500 & & 496.9 & 479.4 & 514.4 & 1 & & & & & 516.3 & 499.7 & 532.9 & 1 & & & & \\
\hline & 1 & 2 & 600 & 100 & 628.5 & 603.9 & 653.2 & 0 & 131.6 & 0 & 0 & 0 & 594.1 & 573.8 & 614.5 & 1 & 77.8 & 0 & 0 & 0 \\
\hline & & 3 & 500 & -100 & 505.2 & 490.7 & 519.7 & 1 & -123.4 & 0 & 0 & 0 & 503.1 & 488.4 & 517.8 & 1 & -91 & 0 & 0 & 0 \\
\hline
\end{tabular}

\footnotetext{
${ }^{\mathrm{a}}$ It is the theoretical size of the change in the price respect to the previous period (or respect 500 for period 1 Series Two, i.e. year 2,3,4)

${ }^{b} 1$ means that the expected value (theoretical prediction) is in the interval of confidence of the estimated price

${ }^{c}$ It is the empirical size of the change in the price respect to the previous period (or respect 500 for period 1 Series Two, i.e. year 2,3,4)

d 1 means a bubble, which is a movement in the wrong direction and the interval of confidence of the estimated price contains values that, in absolute value, differ at least of 100 from the correct equilibrium.

e 1 means a mirage that is the interval of confidence of the estimated price contains values that, in absolute value, differ at least of 100 from the correct equilibrium and the movement is in the right direction.

${ }^{\mathrm{f}} 1$ means that there is not a statistical difference between the price of current period and that of the past period (or respect 500 for period 1 Series Two, i.e. year $2,3,4)$.
} 


\begin{tabular}{|c|c|c|c|c|c|c|c|c|c|c|c|c|c|c|c|c|c|c|c|c|}
\hline & & 1 & 600 & 100 & 593.4 & 577.6 & 609.3 & 1 & 93.4 & 0 & 0 & 0 & 562.6 & 546.9 & 578.2 & 0 & 62.6 & 0 & 0 & 0 \\
\hline & 2 & 2 & 500 & -100 & 440.8 & 394.5 & 487.1 & 0 & -152.7 & 0 & 1 & 0 & 511.7 & 482.6 & 540.7 & 1 & -50.9 & 0 & 0 & 0 \\
\hline & & 3 & 600 & 100 & 589.2 & 555.4 & 623 & 1 & 148.4 & 0 & 0 & 0 & 595.7 & 571.4 & 620 & 1 & 84.1 & 0 & 0 & 0 \\
\hline & & 1 & 400 & -100 & 545.6 & 522.9 & 568.3 & 0 & 45.6 & 1 & 0 & 0 & 525.3 & 505.9 & 544.8 & 0 & 25.3 & 1 & 0 & 0 \\
\hline & 3 & 2 & 300 & -100 & 443.1 & 367.2 & 519 & 0 & -102.5 & 0 & 1 & 0 & 439.6 & 402.6 & 476.7 & 0 & -85.7 & 0 & 1 & 0 \\
\hline & & 3 & 200 & -100 & 142.9 & 29.6 & 256.3 & 1 & -300.1 & 0 & 0 & 0 & 295.5 & 249.1 & 341.8 & 0 & -144.2 & 0 & 1 & 0 \\
\hline & & 1 & 400 & -100 & 616.4 & 602.5 & 630.3 & 0 & 116.4 & 1 & 0 & 0 & 597.1 & 582.7 & 611.5 & 0 & 97.1 & 1 & 0 & 0 \\
\hline & 4 & 2 & 500 & 100 & 686.9 & 659.9 & 713.9 & 0 & 70.5 & 0 & 1 & 0 & 696.1 & 674.7 & 717.6 & 0 & 99.1 & 0 & 1 & 0 \\
\hline & & 3 & 600 & 100 & 577.4 & 560.8 & 594 & 0 & -109.5 & 0 & 0 & 0 & 589.6 & 573.4 & 605.7 & 1 & -106.6 & 0 & 0 & 0 \\
\hline |040513| & & 1 & 500 & & 443.5 & 433.7 & 453.3 & 0 & & & & & 456.3 & 444.9 & 467.6 & 0 & & & & \\
\hline & 1 & 2 & 400 & -100 & 430.9 & 400.9 & 460.9 & 0 & -12.6 & 0 & 0 & 1 & 428.1 & 405.4 & 450.8 & 0 & -28.2 & 0 & 0 & 0 \\
\hline & & 3 & 300 & -100 & 307.2 & 260.9 & 353.5 & 1 & -123.7 & 0 & 0 & 0 & 317.7 & 289 & 346.4 & 1 & -110.4 & 0 & 0 & 0 \\
\hline & & 1 & 600 & 100 & 598.3 & 573.7 & 622.9 & 1 & 98.3 & 0 & 0 & 0 & 566 & 545.6 & 586.4 & 0 & 66 & 0 & 0 & 0 \\
\hline & 2 & 2 & 500 & -100 & 454.4 & 378.5 & 530.3 & 1 & -143.9 & 0 & 0 & 0 & 503.7 & 466.5 & 540.9 & 1 & -62.3 & 0 & 0 & 0 \\
\hline & & 3 & 400 & -100 & 397.6 & 370.6 & 424.6 & 1 & -56.8 & 0 & 0 & 1 & 410.8 & 389.3 & 432.2 & 1 & -92.9 & 0 & 0 & 0 \\
\hline & & 1 & 400 & -100 & 416.8 & 383 & 450.7 & 1 & -83.2 & 0 & 0 & 0 & 424 & 399.7 & 448.4 & 1 & -76 & 0 & 0 & 0 \\
\hline & 3 & 2 & 500 & 100 & 452.5 & 435.9 & 469.1 & 0 & 35.7 & 0 & 0 & 1 & 437.8 & 421.8 & 453.9 & 0 & 13.8 & 0 & 0 & 1 \\
\hline & & 3 & 600 & 100 & 568.2 & 548.5 & 587.9 & 0 & 115.7 & 0 & 0 & 0 & 535.3 & 517.4 & 553.3 & 0 & 97.5 & 0 & 0 & 0 \\
\hline & & 1 & 600 & 100 & 605.7 & 584.6 & 626.7 & 1 & 105.7 & 0 & 0 & 0 & 594 & 575.4 & 612.6 & 1 & 94 & 0 & 0 & 0 \\
\hline & 4 & 2 & 500 & -100 & 560.6 & 530.6 & 590.6 & 0 & -45.1 & 0 & 0 & 0 & 539.4 & 516.6 & 562.1 & 0 & -54.7 & 0 & 0 & 0 \\
\hline & & 3 & 600 & 100 & 600.9 & 487.5 & 714.3 & 1 & 40.3 & 0 & 0 & 1 & 596.9 & 551.5 & 642.3 & 1 & 57.5 & 0 & 0 & 0 \\
\hline 040524 & & 1 & 500 & & 516.9 & 505.8 & 528 & 0 & & & & & 517.6 & 505.3 & 530 & 0 & & & & \\
\hline & 1 & 2 & 600 & 100 & 603.5 & 592.7 & 614.3 & 1 & 86.6 & 0 & 0 & 0 & 602 & 589.9 & 614.2 & 1 & 84.4 & 0 & 0 & 0 \\
\hline & & 3 & 700 & 100 & 694.3 & 685.7 & 703 & 1 & 90.8 & 0 & 0 & 0 & 694.6 & 684.2 & 705 & 1 & 92.6 & 0 & 0 & 0 \\
\hline & & 1 & 600 & 100 & 597.9 & 587.4 & 608.4 & 1 & 97.9 & 0 & 0 & 0 & 588.5 & 576.6 & 600.5 & 1 & 88.5 & 0 & 0 & 0 \\
\hline & 2 & 2 & 500 & -100 & 499.4 & 487.7 & 511.2 & 1 & -98.5 & 0 & 0 & 0 & 517 & 504.2 & 529.9 & 0 & -71.5 & 0 & 0 & 0 \\
\hline & & 3 & 400 & -100 & 399.1 & 382.5 & 415.7 & 1 & -100.3 & 0 & 0 & 0 & 401.5 & 385.4 & 417.6 & 1 & -115.5 & 0 & 0 & 0 \\
\hline & & 1 & 600 & 100 & 605.9 & 594.8 & 617 & 1 & 105.9 & 0 & 0 & 0 & 594 & 581.7 & 606.4 & 1 & 94 & 0 & 0 & 0 \\
\hline & 3 & 2 & 700 & 100 & 689.7 & 678 & 701.5 & 1 & 83.8 & 0 & 0 & 0 & 678.5 & 665.6 & 691.3 & 0 & 84.4 & 0 & 0 & 0 \\
\hline & & 3 & 600 & -100 & 605.1 & 580.5 & 629.7 & 1 & -84.6 & 0 & 0 & 0 & 599.7 & 579.4 & 620.1 & 1 & -78.7 & 0 & 0 & 0 \\
\hline & & 1 & 400 & -100 & 412.6 & 403.1 & 422.2 & 0 & -87.4 & 0 & 0 & 0 & 424.9 & 413.7 & 436.1 & 0 & -75.1 & 0 & 0 & 0 \\
\hline & 4 & 2 & 500 & 100 & 486 & 476.4 & 495.6 & 0 & 73.4 & 0 & 0 & 0 & 468.9 & 457.7 & 480.1 & 0 & 43.9 & 0 & 0 & 0 \\
\hline & & 3 & 600 & 100 & 613.6 & 583.6 & 643.6 & 1 & 127.6 & 0 & 0 & 0 & 582.8 & 560 & 605.6 & 1 & 113.9 & 0 & 0 & 0 \\
\hline 040527 & 1 & 1 & 500 & & 511.8 & 490.7 & 532.9 & 1 & & & & & 509.5 & 491 & 528.1 & 1 & & & & \\
\hline & & 2 & 600 & 100 & 609.6 & 597.4 & 621.7 & 1 & 97.8 & 0 & 0 & 0 & 603.5 & 590.4 & 616.6 & 1 & 94 & 0 & 0 & 0 \\
\hline
\end{tabular}




\begin{tabular}{|c|c|c|c|c|c|c|c|c|c|c|c|c|c|c|c|c|c|c|c|}
\hline & 3 & 500 & -100 & 513.2 & 499.2 & 527.1 & 1 & -96.4 & 0 & 0 & 0 & 510.3 & 496 & 524.7 & 1 & -93.2 & 0 & 0 & 0 \\
\hline \multirow{4}{*}{2} & 1 & 600 & 100 & 606 & 583.3 & 628.7 & 1 & 106 & 0 & 0 & 0 & 590.3 & 570.9 & 609.6 & 1 & 90.3 & 0 & 0 & 0 \\
\hline & 2 & 700 & 100 & 512.6 & 473.6 & 551.6 & 0 & -93.5 & 1 & 0 & 0 & 559 & 532.6 & 585.4 & 0 & -31.2 & 1 & 0 & 1 \\
\hline & 3 & 800 & 100 & 632.1 & 612.3 & 651.8 & 0 & 119.5 & 0 & 1 & 0 & 603.5 & 585.6 & 621.4 & 0 & 44.4 & 0 & 1 & 0 \\
\hline & 1 & 600 & 100 & 594.1 & 571.4 & 616.8 & 1 & 94.1 & 0 & 0 & 0 & 590.1 & 570.8 & 609.5 & 1 & 90.1 & 0 & 0 & 0 \\
\hline \multirow[t]{3}{*}{3} & 2 & 500 & -100 & 554.3 & 529.6 & 578.9 & 0 & -39.8 & 0 & 0 & 0 & 568 & 547.6 & 588.3 & 0 & -22.2 & 0 & 0 & 1 \\
\hline & 3 & 400 & -100 & 459.9 & 432.9 & 487 & 0 & -94.3 & 0 & 0 & 0 & 450 & 428.5 & 471.4 & 0 & -118 & 0 & 0 & 0 \\
\hline & 1 & 600 & 100 & 597.3 & 578.8 & 615.9 & 1 & 97.3 & 0 & 0 & 0 & 579.5 & 562.3 & 596.7 & 0 & 79.5 & 0 & 0 & 0 \\
\hline \multirow[t]{2}{*}{4} & 2 & 500 & -100 & 498.5 & 441.2 & 555.8 & 1 & -98.8 & 0 & 0 & 0 & 503.4 & 471.3 & 535.5 & 1 & -76.1 & 0 & 0 & 0 \\
\hline & 3 & 400 & -100 & 387.4 & 341.1 & 433.7 & 1 & -111.1 & 0 & 0 & 0 & 418.6 & 389.8 & 447.5 & 1 & -84.8 & 0 & 0 & 0 \\
\hline
\end{tabular}


Table 3: Limit orders by informed and uninformed agents in all periods.

\begin{tabular}{cccccc}
\hline Minute & $\begin{array}{c}\text { Agents } \\
\text { Uninformed }\end{array}$ & $\begin{array}{c}\text { Ratio } \\
\text { Informed }\end{array}$ & $\begin{array}{c}\text { Total } \\
\text { informed to } \\
\text { uninformed }\end{array}$ & $\begin{array}{c}\text { Test on } \\
\text { independence }\end{array}$ \\
\hline 1 & 41 & 55 & 96 & 1.34 & \\
2 & 55 & 38 & 93 & 0.69 & Pearson chi2 $(4)=$ \\
3 & 79 & 58 & 137 & 0.73 & 15.9837 \\
4 & 103 & 50 & 153 & 0.49 & Pr $=0.003$ \\
5 & 95 & 56 & 151 & 0.59 & \\
Total & 373 & 257 & 630 & 0.69 & \\
\hline
\end{tabular}

Table 4: Limit orders by informed and uninformed agents in non-bubble-mirage periods

\begin{tabular}{|c|c|c|c|c|c|}
\hline \multirow[b]{2}{*}{ Minute } & \multicolumn{2}{|c|}{ Agents type } & \multirow[b]{2}{*}{ Total } & \multirow{2}{*}{\begin{tabular}{l}
\multicolumn{1}{c}{ Ratio } \\
informed to \\
uninformed
\end{tabular}} & \multirow{2}{*}{$\begin{array}{c}\text { Test on } \\
\text { independence }\end{array}$} \\
\hline & Uninformed & Informed & & & \\
\hline 1 & 32 & 50 & 82 & 1.56 & \multirow{6}{*}{$\begin{array}{c}\text { Pearson chi2 }(4) \\
14.5165 \\
\operatorname{Pr}=0.006\end{array}$} \\
\hline 2 & 48 & 34 & 82 & 0.71 & \\
\hline 3 & 70 & 53 & 123 & 0.76 & \\
\hline 4 & 86 & 47 & 133 & 0.55 & \\
\hline 5 & 79 & 53 & 132 & 0.67 & \\
\hline Total & 315 & 237 & 552 & 0.75 & \\
\hline
\end{tabular}

Table 5: Limit orders by informed and uninformed agents in periods with a bubble or mirage.

\begin{tabular}{|c|c|c|c|c|c|}
\hline \multirow[b]{2}{*}{ Minute } & \multicolumn{2}{|c|}{ Agents type } & \multirow[b]{2}{*}{ Total } & \multirow{2}{*}{$\begin{array}{c}\text { Ratio } \\
\text { informed to } \\
\text { uninformed }\end{array}$} & \multirow{2}{*}{$\begin{array}{c}\text { Test on } \\
\text { independence }\end{array}$} \\
\hline & Uninformed & Informed & & & \\
\hline 1 & 9 & 5 & 14 & 0.56 & \multirow{6}{*}{$\begin{array}{c}\text { Pearson chi2 (4) } \\
4.3084 \\
\operatorname{Pr}=0.366\end{array}$} \\
\hline 2 & 7 & 4 & 11 & 0.57 & \\
\hline 3 & 9 & 5 & 14 & 0.56 & \\
\hline 4 & 17 & 3 & 20 & 0.18 & \\
\hline 5 & 16 & 3 & 19 & 0.19 & \\
\hline Total & 58 & 20 & 78 & 0.34 & \\
\hline
\end{tabular}

Table 6: Probability that a limit order is placed by an informed agent as a function of time, a probit estimation.

a) In periods with a bubble or mirage

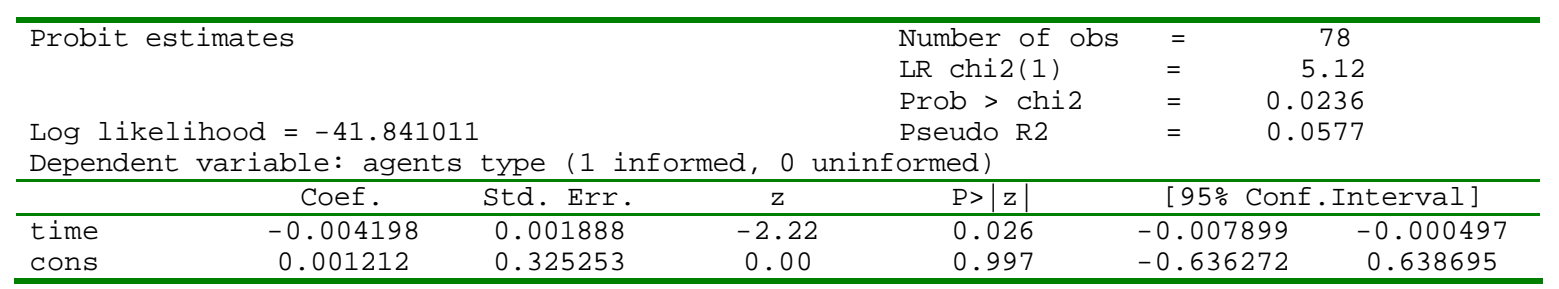

b) In non-bubble-mirage periods according

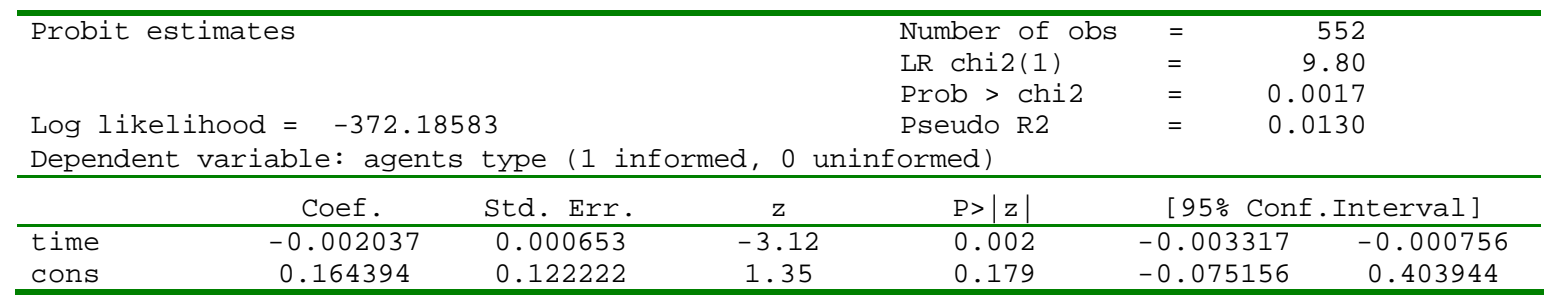


Table7. Limit orders by informed and uninformed agents by minute and by level of information aggregation (bubble and mirage periods vs. non-bubble-mirage periods)

\begin{tabular}{|c|c|c|c|c|c|}
\hline \multirow{2}{*}{ Minute } & \multicolumn{2}{|c|}{$\begin{array}{c}\text { Ratio of limit orders by } \\
\text { informed to limit orders } \\
\text { in total }\end{array}$} & \multirow{2}{*}{$\begin{array}{l}\text { Difference } \\
(1)-(2)\end{array}$} & \multirow{2}{*}{$z$-test ${ }^{a}$} & \multirow{2}{*}{ p-value } \\
\hline & $\begin{array}{l}\text { Bubble and } \\
\text { mirage } \\
\text { periods (1) }\end{array}$ & $\begin{array}{l}\text { Non-bubble- } \\
\text { mirage } \\
\text { periods (2) }\end{array}$ & & & \\
\hline 1 & 0.36 & 0.61 & -0.25 & -1.766 & 0.0387 \\
\hline 2 & 0.36 & 0.41 & -0.05 & -0.3231 & 0.37331 \\
\hline 3 & 0.36 & 0.43 & -0.07 & -0.5292 & 0.29833 \\
\hline 4 & 0.15 & 0.35 & -0.2 & -1.808 & 0.0353 \\
\hline 5 & 0.16 & 0.4 & -0.24 & -2.0555 & 0.01992 \\
\hline
\end{tabular}

${ }^{a}$ Null hypothesis: difference (1)-(2)=0 